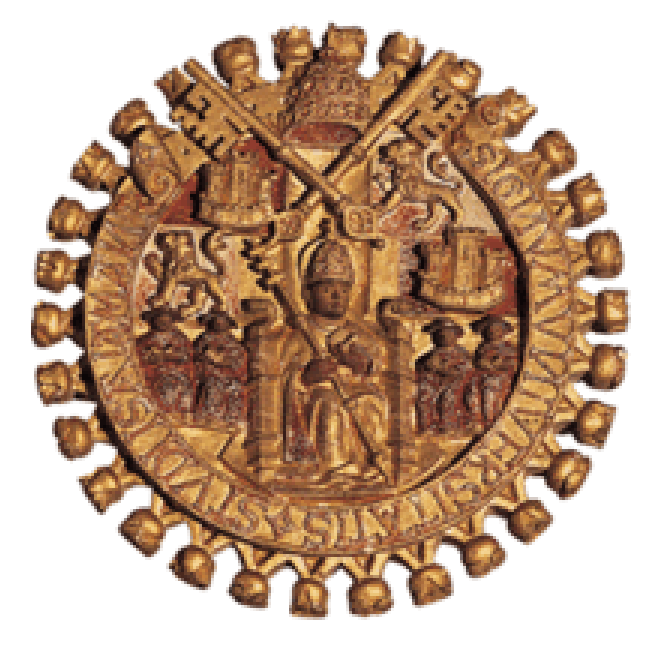

\title{
FUNCIÓN TIROIDEA Y MORTALIDAD EN PACIENTES ANCIANOS HOSPITALIZADOS
}

\section{TESIS DOCTORAL}

Elena Ridruejo Gutiérrez de la Cámara

Facultad de Medicina

Universidad de Salamanca

Salamanca, 2014 
TESIS DOCTORAL: FUNCIÓN TIROIDEA Y MORTALIDAD EN PACIENTES ANCIANOS HOSPITALIZADOS

DOCTORANDA: ELENA RIDRUEJO GUTIÉRREZ DE LA CÁMARA

Memoria para optar al grado de Doctor por la Universidad de Salamanca.

D. MANUEL HERAS BENITO, Licenciado en Medicina y Cirugía por la Universidad de Salamanca y Especialista en Nefrología (Hospital General de Segovia); Doctor en Medicina por la Universidad de Salamanca.

D. PEDRO IGLESIAS LOZANO, Licenciado en Medicina y Cirugía por la Universidad Complutense de Madrid y Especialista en Endocrinología y Nutrición (Hospital Universitario Ramón y Cajal de Madrid); Doctor en Medicina por la Universidad Autónoma de Madrid.

D. DANIEL TORANZO MARTíNEZ, Licenciado en Medicina y Cirugía por la Universidad de Salamanca; Doctor en Medicina y Cirugía por la Universidad de Salamanca; Profesor Titular y Catedrático de Escuela Universitaria en Anatomía e Histología Humanas de la Universidad de Salamanca. 
INFORMAN:

Que el trabajo titulado "FUNCIÓN TIROIDEA Y MORTALIDAD EN PACIENTES ANCIANOS HOSPITALIZADOS" realizado por Dạ ELENA RIDRUEJO GUTIÉRREZ DE LA CÁMARA, Licenciada en Medicina y Cirugía por la Universidad de Salamanca y Especialista en Geriatría, ha sido llevado a cabo bajo nuestra dirección y se encuentra en condiciones de ser presentado como Tesis Doctoral ante el tribunal correspondiente.

Y para que así conste, firmamos el presente informe en Salamanca, a 10 de Julio de 2014.

Dr. Manuel Heras Benito

Dr. Pedro Iglesias Lozano

Dr. Daniel Toranzo Martínez 


\section{AGRADECIMIENTOS}

Empezaré dando gracias a esta tesis ya que ella es la excusa perfecta para deciros cuanto os quiero, qué importantes sois cada uno de vosotros en mi vida y daros las gracias por ello. Nada hubiera sido posible sin vosotros: mi familia, mis amigos, mis maestros, mis compañeros y alguno de mis pacientes que me han llegado al corazón y también forman parte de mi experiencia vital, no sólo de mi profesión.

También quiero dar las gracias a esta profesión, una profesión preciosa, quizás la única profesión que merece la pena vivirla en plenitud, la profesión con mayúsculas porque es una forma de entrega, de servicio, que hace que quienes la ejercemos con vocación y amor, seamos unos privilegiados por poder transformar el conocimiento en vida, en salud, o al menos consuelo o alivio, ya que estamos al lado de quienes nos necesitan en los momentos más bonitos o tristes $y$, en cualquier caso, más especiales de sus vidas. Todo ello realmente es algo que da sentido a la vida, desde luego a mi vida.

Por ello, vosotros y mi profesión sois todo para mí. Gracias:

Mi familia:

- A mi familia, mis raíces, mi vida, por haber estado siempre a mi lado y en todos los momentos, en especial mis padres y mis hermanos. Ellos me ayudaron durante la realización de mi carrera, y sin ellos, hoy no sería médico ni hubiese llegado a ser quien soy, como persona y como profesional. Fueron ellos quienes me han enseñado lo importante de la vida, querer y sentirte querido. Vosotros sois un verdadero ejemplo para mí porque en casa aprendí el sentido de la generosidad y el amor a los demás, lo que me permitió elegir esta carrera. A Juan, un pequeñajo al que estamos deseando conocer; y en especial y con gran cariño, a mi hermana Marta.

- A Pepe y a mis hijos Daniela y Álvaro, me ayudáis a caminar con profunda ilusión, haría cualquier cosa por vosotros, sois mi luz, mi esencia, mi amor, mis dos grandes tesoros. Pepe, conocerte y tener a nuestros hijos ha culminado mis sueños, los tres sois mi vida. Gracias desde lo más profundo de mi alma por dar plenitud y sentido a mi vida, espero enseñar a mis hijos los grandes valores y lo que realmente importa de la vida, como lo hicieron mis padres. Pepe, sé que tú eres un padre maravilloso y no te será difícil ayudarme y compartir felizmente el camino.

- A Concha, Pepín, Keko, María y Ana, muchas gracias por regalarme vuestro cariño, por irradiar alegría, optimismo y haber estado siempre a nuestro lado; muchas gracias por querer como sabéis querer, de una forma plena y especial. 
Mis maestros:

- Al Dr. D. Manuel Heras Benito, por ser como es, tan excepcional profesional como persona, deseo que no cambies nunca y la mayor felicidad en tu vida. Gracias por tu apoyo constante y ayuda.

- Al Dr. D. Pedro Iglesias Lozano, organizador y pilar básico del proyecto, quien desde el primer día permitió ilusionarme con poder defender mi tesis doctoral. Es un honor que contases con nosotros en diferentes proyectos y poder trabajar contigo. Gracias por todo.

- Al Prof. Dr. D. Daniel Toranzo Martínez, quien aceptó el proyecto para poder exponerlo en la Universidad de Salamanca. Sin su impulso, su buen hacer, esto no hubiese llegado a su fin. Muchas gracias por tu generosidad.

- Al Dr. D. Juan José Díez, por haber colaborado desde el inicio en este proyecto y apoyarlo en todo momento. Gracias por tu sabiduría.

A mis compañeros:

- A todas las personas que forman parte del Servicio de Geriatría del Hospital General de Segovia, D. Florentino Prado, jefe del Servicio de Geriatría, Dá María Cruz Macías, Da María Teresa Guerrero, Da Luciana Miguel, Dạ Flavia Lorena Hunicken y, en especial, a Dạ Angélica Muñoz, por su colaboración, trabajo, apoyo y ánimo. Gracias por el camino recorrido juntos, por haberme enseñado tantos conocimientos sobre medicina y también sobre la vida, gracias por hacer de nuestro servicio, un servicio especial y, además, gracias por haber compartido conmigo vuestra vocación de entrega, por dar valor y trascendencia a la labor bien hecha, gracias por vuestro apoyo constante e inalterable. Luchar junto a vosotros por esta profesión es todo un lujo.

- También al Servicio de Análisis Clínicos del Hospital General de Segovia, Dạ Pilar Tajada y Dạ Carmen García Arévalo, por su colaboración, apoyo, trabajo, paciencia y alegría; sin vosotras, nada hubiera sido posible.

- Gracias al personal de archivo, Dạ María Rosario Martín Muñoz, y secretariado del Servicio de Geriatría del Hospital General de Segovia, en especial, a Dá Isabel de la Esperanza Martín, sin ellas y de manera voluntaria, no se hubiese podido iniciar la recogida de datos $y$, por tanto, la realización de esta tesis. Gracias Isa, ya sabes lo especial que eres. 
A mis amigos, por su apoyo, su cariño y comprensión, en especial a:

- Helena Ayuso Pecharromán, quien siempre me apoyó y me ayudó a centrarme y a continuar en los momentos difíciles; siempre generosa, siempre atenta, siempre amiga.

- Elena Herrero Goñi, por su sincera, leal y eterna amistad. Siempre a tu lado.

- Alejandro Tomillo, mi primer y gran amigo y a quien deseo la mayor felicidad en esta vida. Tú me enseñaste la profundidad del sentir, a soñar, la lealtad y sinceridad entre amigos.

- Isabel Rivas Pollmar, por todo tu cariño y auténtica amistad a pesar de la distancia. Te llevo a ti y a tus padres siempre conmigo.

- A Víctor y a Fuen, no te olvido. Ojalá la medicina nos hubiera enseñado a curarte a ti y a todas las personas que sufren.

Y a mi familia y amigos deciros que sé que sabéis perdonar mis periodos de ausencia y algunos pequeños despistes, que no fueron nunca causados por falta de cariño, sólo por falta de tiempo. Ser madre, médico, hija, hermana... no siempre es fácil.

Pero también quiero decir que una vida es muy larga y muy intensa $y$, por suerte, en mi camino me he encontrado con gente maravillosa; ellos saben quiénes son y saben que forman también parte de mi corazón y lo hacen con palabras mayores aunque no pueda aquí nombrar a cada uno ellos, pues no dejaría espacio para la tesis y sólo me dedicaría a poner el nombre de tantas personas admirables que me acompañan, me han dado y me dan su calor a lo largo del camino... lo que me hace pensar que esta vida merece y mucho la pena, porque hay gente buena, hay gente increíble, y porque compartirla con ellos está siendo todo un regalo.

Nada hubiera sido posible sin cada uno de vosotros, ha sido cada una de vuestras sonrisas, ánimos, manos tendidas, miradas, mensajes, indicaciones... lo que ha hecho posible este trabajo, fruto del esfuerzo pero, sin duda y, en gran medida, lo es de vuestra labor.

Os quiero 

TíTULo

Función tiroidea y mortalidad en pacientes ancianos hospitalizados. 


\section{ÍNDICE}

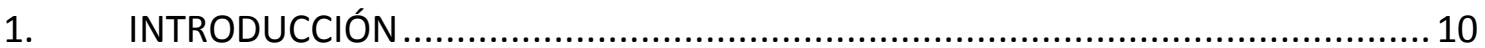

1.1. Breve recuerdo embriológico y anatómico de la glándula tiroides ............... 10

1.2. Cambios en la función y morfología tiroidea asociados a la edad................. 11

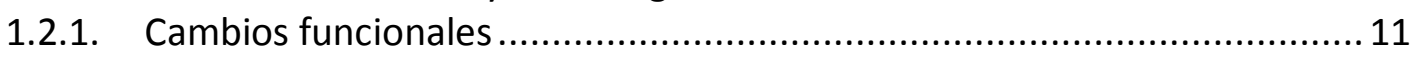

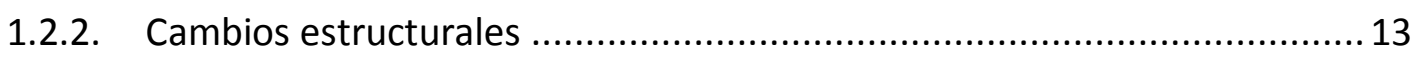

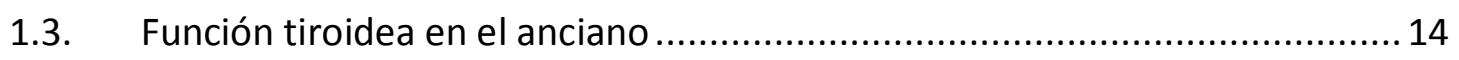

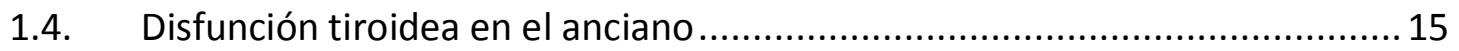

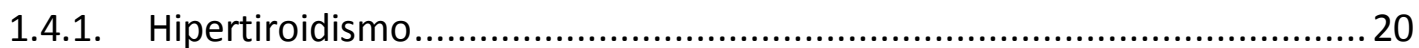

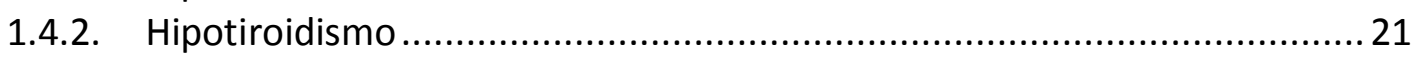

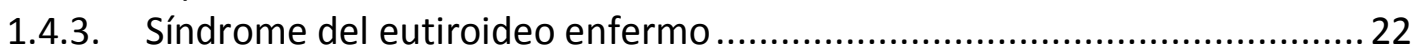

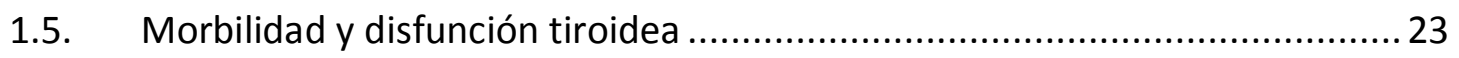

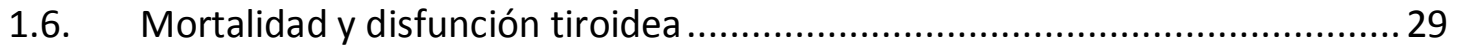

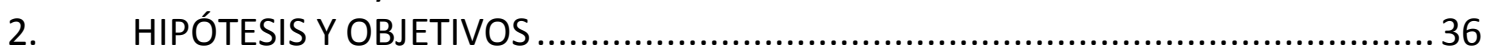

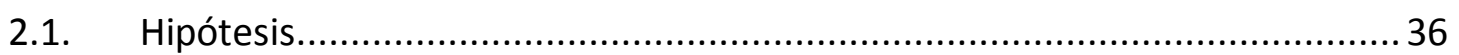

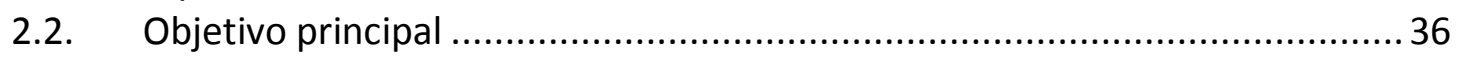

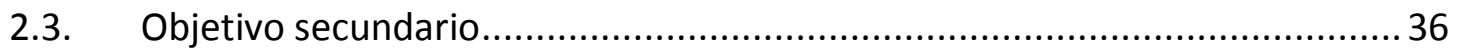

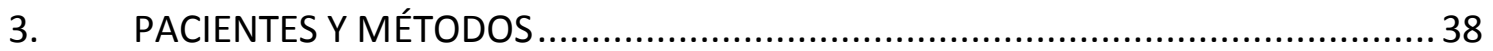

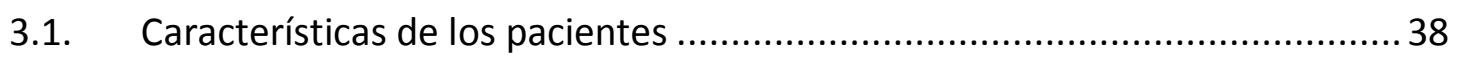

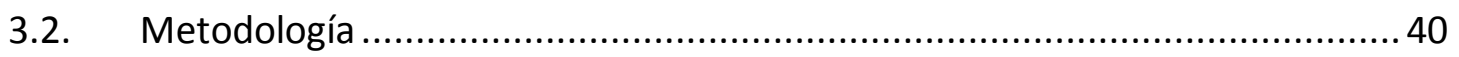

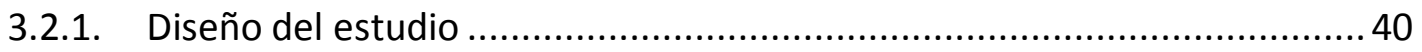

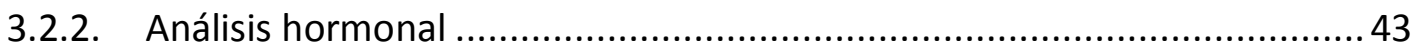

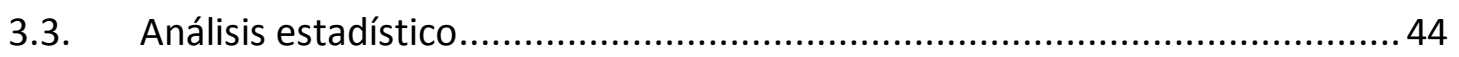

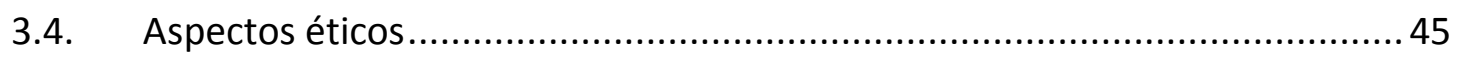

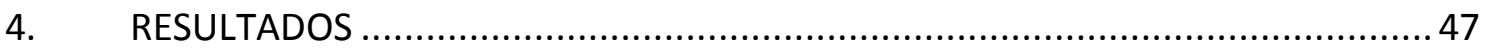

4.1. Pruebas de función tiroidea y morbilidad ................................................. 47

4.2. Pruebas de función tiroidea y mortalidad ..................................................... 50

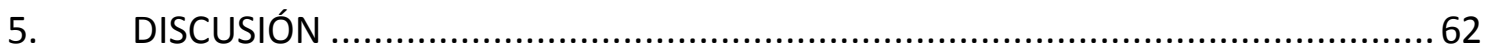

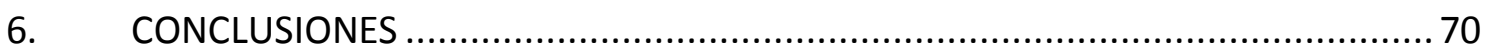

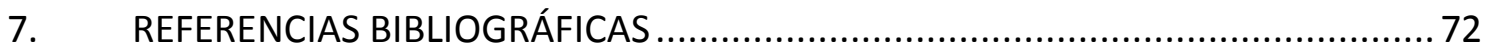

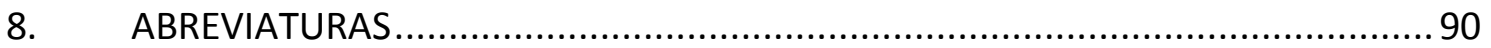

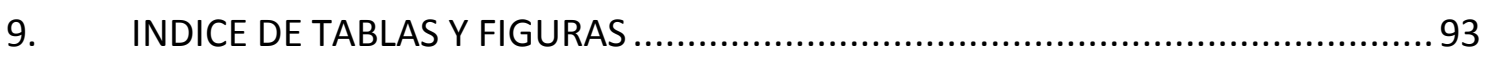

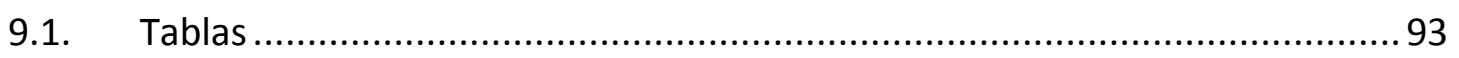

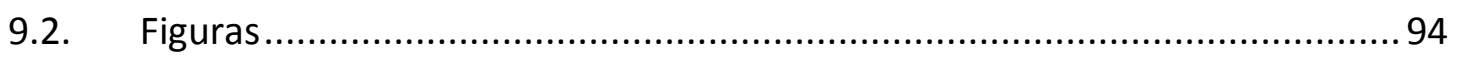

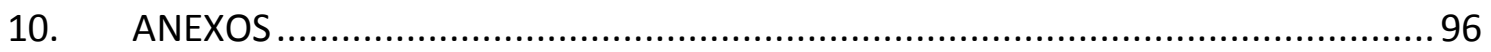

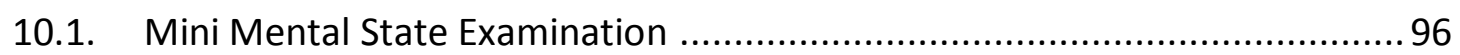

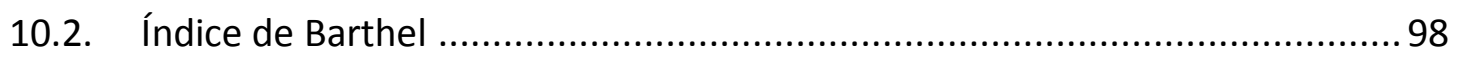





\section{INTRODUCCIÓN}

Los cambios en la función de la glándula tiroides asociados al envejecimiento se conocen desde hace más de 20 años (1), pero sólo algunos estudios recientes centran sus investigaciones en el papel de eje hipotálamo-hipófisis-tiroideo (HHT) en los ancianos (2-9).

\subsection{Breve recuerdo embriológico y anatómico de la glándula tiroides}

El correcto desarrollo y funcionamiento de la glándula tiroides requiere de la existencia de dos tipos celulares de diferente procedencia embrionaria: las células foliculares o tirocitos y las células parafoliculares o células C. Las primeras, proceden del primordio tiroideo medio, es decir, de un engrosamiento del epitelio endodérmico en la porción craneal del intestino anterior (faringe), procedente del segundo arco branquial. Por el contrario, las células parafoliculares tienen su origen en la cresta neural embrionaria, a través de los primordios tiroideos laterales que, a su vez, provienen de los cuartos y quintos arcos branquiales (10).

Las hormonas tiroideas, tiroxina o tetrayodotirosina (T4) y triyodotironina (T3), se sintetizan en el coloide del folículo tiroideo, la unidad anatómica y funcional de la glándula tiroides, recubierta por las células foliculares, mientras que la calcitonina se sintetiza en las células parafoliculares.

Morfológicamente, la glándula tiroides está constituida por dos lóbulos unidos por el istmo, que suele estar situado sobre los tres primeros anillos traqueales. 
La vascularización corre a cargo de las arterias tiroideas superiores que, a su vez, provienen de las arterias carótidas externas, y las arterias tiroideas inferiores, procedentes de las arterias subclavias (11).

El sistema venoso es menos constante en número y tamaño: las venas tiroideas superiores y medias drenan en la vena yugular interna, y las venas tiroideas inferiores, drenan al tronco braquiocefálico.

El sistema linfático se encuentra formando un plexo subglandular, siendo los colectores principales los medios (superiores e inferiores) y los laterales. El drenaje linfático se hace a través de los ganglios yugulares profundos medios e inferiores, pretraqueales y mediastínicos (12).

La inervación de la glándula tiroides corre a cargo del X par craneal (nervio vago) y el plexo simpático cervical. Los nervios recurrentes, que nacen del nervio vago, se sitúan 1-2 cm laterales a la tráquea, en el polo inferior de la glándula tiroides. Los nervios laríngeos superiores se dividen a nivel del hueso hioides en una rama interna (sensorial) y una externa (motora), que inerva al cricoides, músculo que tensa las cuerdas vocales (13).

\subsection{Cambios en la función y morfología tiroidea asociados a la edad}

\subsubsection{Cambios funcionales}

El envejecimiento se acompaña de cambios en la función tiroidea. Entre ellos se encuentra una reducción, tanto en la captación de yodo, como en la síntesis y secreción de T3 y de T4. Estos cambios han sido interpretados como un mecanismo compensador del descenso de la tasa metabólica basal (1). También se produce una 
disminución en la concentración de T3 por una reducción de la actividad de la desyodasa periférica. La fracción libre de T4 no suele experimentar cambios, mientras que las concentraciones de hormona estimulante del tiroides (TSH) se han encontrado normales, elevadas o reducidas (1).

En la tabla 1 se resumen los principales cambios en la función tiroidea asociados al envejecimiento.

Tabla 1: Cambios en la función tiroidea asociados al envejecimiento (1).

Disminución de la captación absoluta de yodo

Disminución de la captación tiroidea de radioyodo

Disminución de la síntesis y secreción de T4 y T3

Reducción de la tasa metabólica basal

Reducción de la capacidad de unión de las proteínas transportadoras

Disminución de la degradación periférica de T4

Disminución de la actividad de la 5'desyodasa

Concentraciones de T4 total y libres normales

Disminución de la concentración de T3

Concentración de la TSH normal, elevada o reducida

Reducción de las respuestas de TSH a TRH

Reducción de la concentración integrada de TSH 
Las enfermedades no tiroideas agudas y crónicas pueden acompañarse de alteraciones en las pruebas de función tiroidea. El trastorno más común es la disminución de T3 libre (T3 L) (síndrome de T3 baja) y es infrecuente detectar una reducción de T4 libre (T4 L).

Además, con la edad se produce un progresivo aumento en la producción de autoanticuerpos, lo que conlleva un aumento de la probabilidad de desarrollar una hipofunción tiroidea subclínica o manifiesta en el tiempo (1).

Finalmente, diversos agentes farmacológicos pueden alterar el funcionamiento del eje tiroideo, actuando sobre la síntesis y liberación de TSH, y también sobre los procesos de biosíntesis, transporte y metabolismo de las hormonas tiroideas (1). Muchos de estos cambios pueden ser transitorios y no reflejar adecuadamente la fisiología tiroidea del anciano hospitalizado. Sin embargo, estos mismos argumentos serían válidos, aunque con menor intensidad, para los estudios que se han realizado en ancianos de la población general.

\subsubsection{Cambios estructurales}

Con el envejecimiento también se producen cambios en la estructura de la glándula tiroides. Entre ellos, podemos reseñar un aumento de fibrosis interfolicular, disminución en el tamaño de los folículos, degeneración y adelgazamiento de las células foliculares e infiltración por linfocitos. Los folículos se encuentran rellenos de coloide al enlentecerse su resorción, por lo que se acentúa el aplanamiento de las células foliculares. Las células parafoliculares o células $C$, presentan hiperplasia de las mismas, con contenido de diferentes neuropéptidos (14). 
En conclusión, en los ancianos resulta difícil distinguir entre los cambios normales o adaptativos del eje HHT debido a la menor superficie corporal, al descenso de las necesidades energéticas y toma de fármacos. Otro punto a tener en cuenta es la presencia de autoinmunidad tiroidea y de disfunción tiroidea subclínica. A pesar de estos cambios, la glándula tiroidea tiene un normal funcionamiento acorde con las necesidades del anciano (14).

\subsection{Función tiroidea en el anciano}

Las hormonas tiroideas son necesarias para el correcto funcionamiento del organismo. Entre los principales efectos de las hormonas tiroideas en el anciano se encuentran:

- Aceleración del metabolismo de todos los tejidos, excepto retina, bazo, testículos y pulmones $(15,16)$.

- Efecto hiperglucemiante sobre el metabolismo de los hidratos de carbono: intolerancia a la glucosa, inestabilidad glucémica en pacientes diabéticos e insulinorresistencia.

- Regulación del metabolismo de los lípidos al disminuir las concentraciones plasmáticas de colesterol, fosfolípidos y triglicéridos (16).

- Efecto inotrópico negativo y cronotrópico positivo. Aumentan el volumen minuto, la precarga y la presión arterial sistólica. Por el contrario, disminuyen la presión arterial diastólica, la postcarga y las resistencias vasculares sistémicas $(17,18)$.

- Aumento del flujo ventilatorio, en respuesta a la hipoxemia e hipercapnia. 
- Incremento del flujo plasmático renal, el filtrado glomerular (FG) y la reabsorción tubular.

- Estimulación de la síntesis de la unidad formadora de colonias eritrocitarias y de eritropoyetina (EPO); incrementan la agregación y degranulación plaquetaria e inhiben la expresión clonal de la unidad formadora de colonias de granulocitos.

- Aumento del apetito, la absorción de alimentos, la secreción gastrointestinal y la motilidad del tubo digestivo.

- Estimulación, tanto de la osteogénesis como de la osteólisis (16); actúan sobre el desarrollo del esqueleto, la adquisición del pico de masa ósea y el aumento del espesor del hueso cortical.

- Efecto sobre el sistema nervioso central (SNC), encontrándose relación con trastornos de la marcha, el deterioro cognitivo en ancianos y procesos psiquiátricos (19-22).

\subsection{Disfunción tiroidea en el anciano}

La disfunción tiroidea en sus diferentes formas es un trastorno común en la población general $(23,24)$. La figura 1 muestra que el hipotiroidismo franco se presenta con una prevalencia situada entre el 1-7\% (23-27), mientras que estas cifras se incrementan hasta valores de un $14-18 \%$ cuando se considera también el hipotiroidismo subclínico $(28,29)$. La hiperfunción tiroidea se detecta entre un 0,5-3\% de la población general, alcanzando cifras superiores al 5\%, cuando se considera también el hipertiroidismo subclínico $(24,27)$. 
Figura 1. Prevalencia del hipotiroidismo e hipertiroidismo (franco y subclínico) en la población general.

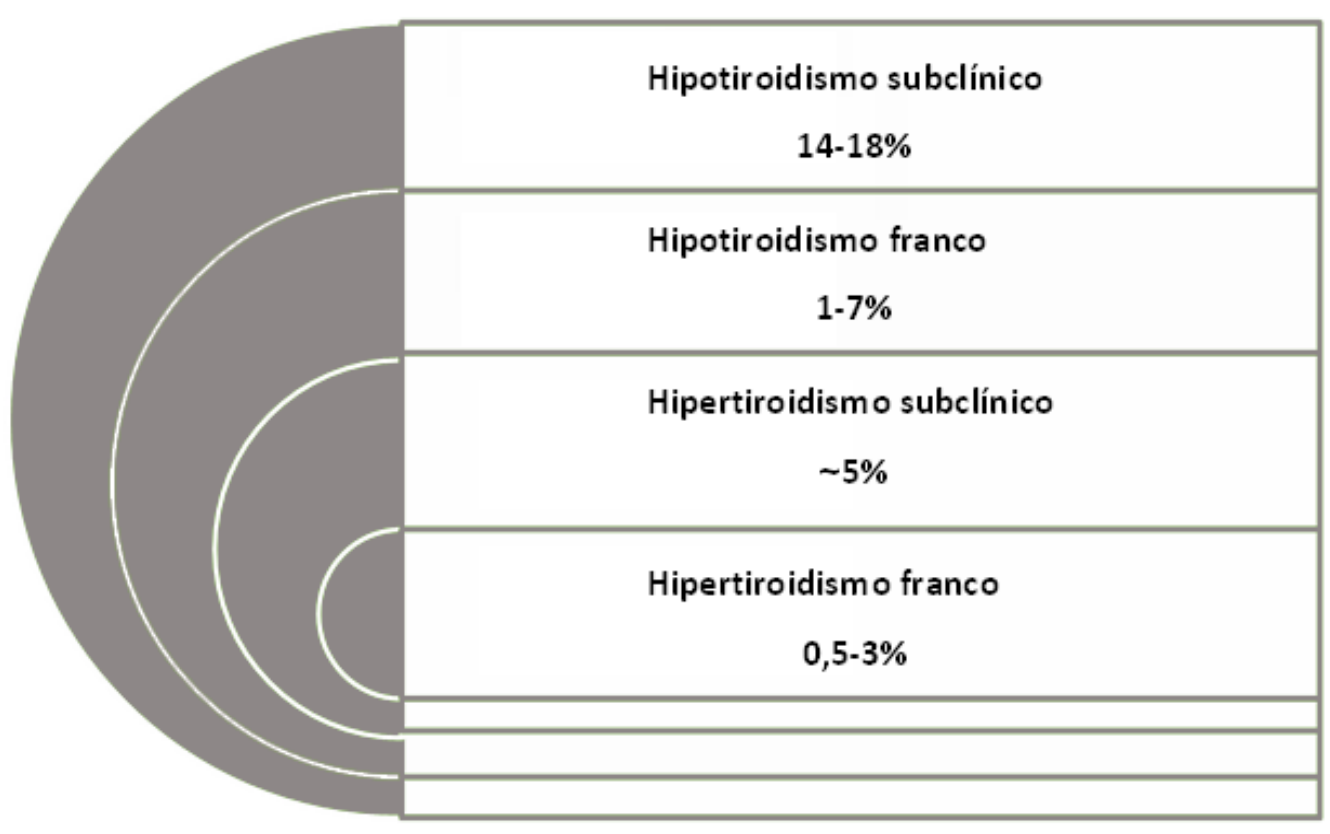

La mayoría de los estudios coinciden en señalar que la prevalencia de disfunción tiroidea es superior en el sexo femenino y se incrementa con la edad (25; 30-37). Un importante estudio descriptivo, de una cohorte de más de 20.000 sujetos, demostró una prevalencia de elevación de TSH del $16 \%$ en hombres y del $21 \%$ en mujeres de edad superior a 74 años (23).

La prevalencia de disfunción tiroidea en personas mayores de 60 años, procedentes de la población general, se ha realizado en dos estudios en el ámbito de la Atención Primaria en nuestro país $(37,38)$. En el estudio Terrassa la prevalencia de disfunción tiroidea global fue de un 13,0\%, y de disfunción tiroidea no diagnosticada previamente de un 4,1\% (38). Por el contrario, en el estudio de Díez y cols. la 
prevalencia total de disfunción tiroidea fue un poco menor, de un 8,5\% (37). Aunque no hubo diferencias significativas en la edad media entre la población analizada en ambos estudios. Sin embargo, el género fue una de las diferencias más llamativas entre ambos estudios: el porcentaje de mujeres fue superior en el estudio de Terrassa frente al estudio de Díez y cols., diferencias de $56 \%$ y $43 \%$, respectivamente. Otra diferencia importante entre los estudios mencionados fueron los criterios utilizados para el diagnóstico de disfunción tiroidea (el estudio de Terrassa definió el hipotiroidismo con una concentración de TSH más elevada que el estudio de Madrid). La prevalencia de nuevos diagnósticos de hipotiroidismo fue ligeramente inferior en el estudio de Madrid (2,0\% frente a 3,6\% en Terrassa), y la del hipertiroidismo fue del 6,4\% (subclínico 6,1\% y clínico, 0,3\%), tal como se muestra en la figura 2 , superior frente a los resultados del estudio Terrassa de un $0,5 \%$. La diferencia en los resultados entre ambos estudios podría deberse a diversos factores, como la distinta metodología empleada en los dos trabajos, la procedencia de los sujetos, la influencia de fármacos y enfermedades no tiroideas, así como la diferente ingesta de yodo. 
Figura 2. Prevalencia de disfunción tiroidea en mayores de 60 años en la Comunidad de Madrid (37)

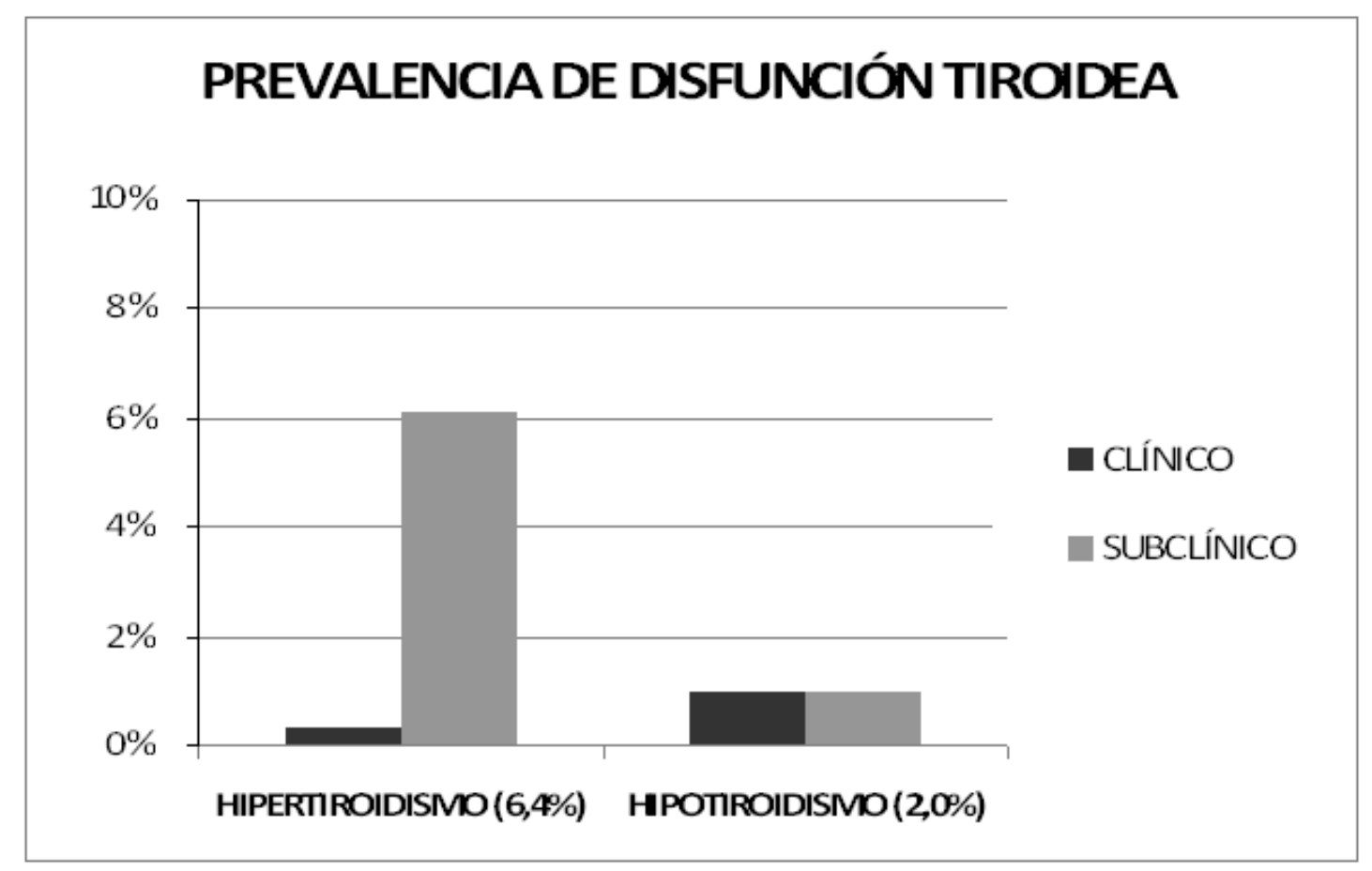

En el ámbito de la Atención Especializada, un trabajo reciente ha estudiado la prevalencia de la disfunción tiroidea en un amplio grupo de pacientes ancianos hospitalizados por cualquier causa, así como la mortalidad intrahospitalaria (39). En este estudio se observó que, aunque solamente el 4,7\% de los pacientes tenían disfunción tiroidea previa al ingreso, sin embargo las alteraciones en las pruebas de función tiroidea eran mucho más frecuentes, llegando a detectarse en aproximadamente tres cuartas partes de la población estudiada en el momento de la hospitalización: el síndrome del eutiroideo enfermo (SEE) fue la alteración más frecuente (62,2 \%). Tras excluir a los pacientes que se diagnosticaron de SEE, el 13,4\% tenían disfunción tiroidea: hipotiroidismo franco (3,1\%); hipotiroidismo subclínico (5,6\%); hipertiroidismo franco (2,5\%) e hipertiroidismo subclínico (2,2 \%). La presencia 
de alteraciones en las pruebas de función tiroidea se asoció positivamente con la edad de los pacientes y con la mortalidad durante la estancia hospitalaria. En este estudio, el principal predictor de mortalidad durante la hospitalización de pacientes de edad avanzada fue la reducción de los niveles de T3 L (39).

Más recientemente, De Alfieri y cols. analizaron un grupo de 450 ancianos ingresados por enfermedad aguda (40) y con características similares al estudio previamente mencionado (39). De Alfieri y cols. encontraron una elevada prevalencia de disfunción tiroidea $(40,7 \%)$ y que, además, aumentaba significativamente con el aumento de la edad (<75 años: $21,2 \%$; $75-84$ años: $34,1 \%$; $\geq 85$ años: $51,5 \%, P<0,001$ ), según se muestra en la tabla 2. En particular, 267 pacientes resultaron eutiroideos, 13 pacientes tenían hipotiroidismo, 27 eran hipertiroideos y casi una tercera parte, es decir, 143 pacientes, tenían SEE.

Tabla 2. Prevalencia de disfunción tiroidea según la edad y género (De Alfieri y cols., 2013).

\begin{tabular}{|c|c|c|c|c|c|c|}
\hline Variables & $\begin{array}{c}\text { Total } \\
(n=450)\end{array}$ & $\begin{array}{l}\text { Eutiroidismo } \\
\qquad(n=267)\end{array}$ & $\begin{array}{l}\text { Hipotiroidismo } \\
\qquad(n=13)\end{array}$ & $\begin{array}{l}\text { Hipertiroidismo } \\
\qquad(n=27)\end{array}$ & $\begin{array}{c}\text { SEE } \\
(n=143)\end{array}$ & $P$ \\
\hline Edad & 83,8 años & 82,6 años & 86,4 años & 85,5 años & 85,4 años & $<0,001$ \\
\hline Grupos edad & & & & & & 0,002 \\
\hline 65-74 años & $7,3 \%$ & $9,7 \%$ & $0 \%$ & $3,7 \%$ & $4,2 \%$ & \\
\hline 75-84 años & $49,6 \%$ & $55,1 \%$ & $30,8 \%$ & $48,1 \%$ & $41,3 \%$ & \\
\hline$>85$ años & $43,1 \%$ & $35,2 \%$ & $69,2 \%$ & $48,1 \%$ & $54,5 \%$ & \\
\hline Mujeres & $66,4 \%$ & $64,4 \%$ & $76,9 \%$ & $77,8 \%$ & $67,1 \%$ & 0,437 \\
\hline
\end{tabular}




\subsubsection{Hipertiroidismo}

El hipertiroidismo puede ser clínico (la TSH está disminuida, o por debajo del límite inferior de la normalidad, y las hormonas tiroideas T3 y T4 se encuentran elevadas), o subclínico (la TSH está disminuida, o por debajo del límite inferior de la normalidad, y las hormonas tiroideas son normales). El hipertiroidismo subclínico, a su vez, se puede dividir en dos subgrupos: con TSH suprimida o indetectable $(<0,1 \mathrm{mU} / \mathrm{L})$ y con TSH baja o parcialmente suprimida $(0,1-0,4 \mathrm{mU} / \mathrm{L})$.

El bocio multinodular hiperfuncionante o tóxico es la etiología más frecuente de hipertiroidismo en los pacientes mayores de 55 años $(43,1 \%)$, seguida de la enfermedad de Graves $(21,4 \%)$ y la tirotoxicosis iatrogénica (16\%). Ciertos fármacos como prednisolona, amiodarona, agonistas dopaminérgicos o el ácido acetilsalicílico pueden producir cambios en la concentración de TSH. Por tanto, la etiología se relaciona con la edad, el sexo, la presencia de bocio, el grado de hipertiroidismo y el estado autoinmune (41).

La severidad de los síntomas del hipertiroidismo clínico varía según el nivel de hormonas tiroideas circulantes (14). El hipertiroidismo se relaciona con la anorexia (32\% de los ancianos frente al 4\% en jóvenes) y la fibrilación auricular (FA) (35\% de los ancianos frente al $2 \%$ en jóvenes). En el hipertiroidismo subclínico también existe riesgo aumentado de FA. Metabólicamente, el grupo más afectado es el hidrocarbonado, relacionándose el hipertiroidismo subclínico con la inestabilidad glucémica. Además, muchos ancianos muestran cambios leves y transitorios en las determinaciones analíticas, por lo que el tratamiento definitivo con yodo radioactivo, resulta en ocasiones innecesario (42). Se recomienda un periodo mínimo de un año de 
seguimiento antes de cualquier tratamiento activo, especialmente en pacientes con niveles de TSH bajos pero detectables, en ausencia de enfermedad nodular o FA (42). Por tanto, existe una necesidad de estrecha vigilancia a los ancianos con hipertiroidismo subclínico (41), por su relación con la mortalidad por todas las causas y con enfermedades circulatorias (14).

\subsubsection{Hipotiroidismo}

El hipotiroidismo clínico se define como la presencia de TSH elevada y T4 L disminuida; sin embargo en el hipotiroidismo subclínico, la TSH se encuentra elevada con T4 y T3 normales.

El hipotiroidismo es más frecuente en la población anciana que en personas más jóvenes (1). La tiroiditis crónica autoinmune y el hipotiroidismo postquirúrgico son las principales causas de la hipofunción tiroidea en mayores de 55 años $(1,43)$. La alta prevalencia de enfermedad tiroidea autoinmune se relaciona con el incremento de la frecuencia de autoanticuerpos y el envejecimiento (1). También, el hipotiroidismo inducido por amiodarona es frecuente en ancianos, principalmente en varones (14).

Su diagnóstico puede resultar difícil, ya que la clínica es más escasa o inespecífica, y se puede confundir con el proceso normal de envejecimiento. Además, otro aspecto a considerar también es que los resultados de las pruebas de función tiroidea pueden alterarse, tanto por el envejecimiento, como por otras enfermedades no tiroideas. Es importante indagar sobre la posible ingesta de fármacos que pueden originar una disminución de la síntesis y secreción de T4 en los ancianos (1). 
Respecto al tratamiento, el hipotiroidismo clínico se trata preferentemente con levotiroxina, mientras que el hipotiroidismo subclínico, por ser potencialmente aterogénico, sólo es recomendable tratarlo cuando la TSH es $>10 \mathrm{mU} / \mathrm{L}$ (14).

El empleo de terapia hormonal sustitutiva con levotiroxina, asociado a un adecuado seguimiento, se asocia a una respuesta terapéutica favorable en más del $80 \%$ de los pacientes en el primer año de seguimiento (43).

\subsubsection{Síndrome del eutiroideo enfermo}

El envejecimiento se acompaña a menudo de disminución en los niveles de T3 debido a una reducción en la actividad de la desyodasa periférica (39). La alteración más frecuente del paciente con SEE es el descenso de las concentraciones de T3; según se agrava la enfermedad también pueden descender los niveles de T4 y TSH, aunque con menos frecuencia (14).

En los pacientes ancianos hospitalizados, el SEE constituye la alteración de las pruebas de función tiroidea más frecuentemente observada, hasta el $62,2 \%$, siendo la prevalencia total de disfunción tiroidea en torno al 74,3\% (39).

Otro estudio relaciona un tipo de SEE, como el síndrome de T3 baja, con baja puntuación en el Mini Mental State Examination (MMSE) (Anexo 10.1) y, también, con peores resultados en la institucionalización y mortalidad intrahospitalaria $(21,44)$. También se ha encontrado una relación entre el síndrome de T3 baja con peor funcionalidad (45).

La albúmina sérica es considerada un predictor de mortalidad en ancianos hospitalizados, y se relacionan las concentraciones séricas de albúmina con los niveles de T3 L; además, existe una relación negativa entre la edad y los niveles de T3 L, que se 
puede explicar por la mencionada disminución de la desyodasa periférica asociada al envejecimiento (39).

\subsection{Morbilidad y disfunción tiroidea}

Las alteraciones en las pruebas de función tiroidea (tanto el hipertiroidismo como el hipotiroidismo) pueden acompañarse de un incremento de trastornos metabólicos y cardiovasculares, que conducen finalmente a un incremento de la morbilidad y la mortalidad (42). En personas de más de 60 años de edad, la presencia de unas concentraciones de TSH suprimidas por debajo de $0,1 \mathrm{mU} / \mathrm{L}$ se asocia a un riesgo relativo de 3,1 para el desarrollo de FA (46), lo cual, a su vez, puede incrementar la mortalidad de origen cardiovascular. Aproximadamente el $6 \%$ de los pacientes con tirotoxicosis o crisis tiroidea desarrollan síntomas de insuficiencia cardiaca congestiva (ICC), y menos del 1\% presentan miocardiopatía dilatada, con posterior disfunción diastólica y sistólica (18).

Por otra parte, el hipotiroidismo franco se ha asociado también a la presencia de enfermedad cardiovascular (ECV). La hipercolesterolemia, la hipertensión diastólica y la disfunción ventricular se han considerado factores que pueden relacionar la hipofunción tiroidea con el aumento del riesgo de ECV y mortalidad (47). El hipotiroidismo franco y, en menor grado el subclínico, puede favorecer el desarrollo de infarto agudo de miocardio (IAM) (48); el nivel de T3 L en rango inferior a la normalidad se correlaciona con un mayor nivel de marcadores cardiacos y menor fracción de eyección del ventrículo izquierdo (FEVI), pudiendo el hipotiroidismo activar la respuesta inflamatoria y, por tanto, ser un predictor de lesión miocárdica en pacientes con síndrome coronario agudo con elevación del ST (SCACEST) $(49,50)$. 
Pfister y cols. (50) demostraron que el síndrome de T3 baja se relacionaba significativamente con la fracción aminoterminal del péptido natriurético cerebral (NTpro-BNP), en pacientes con ECV, contribuyendo por tanto, a un pronóstico adverso y aumento de la mortalidad total y cardiovascular (51).

Respecto al sistema hematoyoyético, en el hipertiroidismo se encuentra aumentada la eritropoyesis, la producción de EPO, los niveles de ferritina y fibrinógeno, así como las concentraciones de factor VIII $(52,53)$. Aproximadamente el $10 \%$ de los pacientes tienen esplenomegalia y aumento del tamaño de los ganglios linfáticos y el timo (54). En cambio, en el hipotiroidismo, es frecuente observar anemia normocítica normocrómica, siendo más frecuente en varones (55). Aproximadamente un $25 \%$ de pacientes con púrpura trombocitopénica idiopática (PTI) en diversos estudios desarrollan hipotiroidismo (56).

Respecto al sistema respiratorio, en los últimos años se han publicado estudios sobre la hipertensión pulmonar (HTP) leve en el paciente hipertiroideo $(57,58)$.

En el hipotiroidismo franco, no sólo se produce disminución en el estímulo del flujo ventilatorio hipóxico, sino también disminución en el estímulo del flujo ventilatorio hipercápnico, pudiendo llegar al coma mixedematoso $(17,59)$. La miopatía periférica y la neuropatía por el compromiso del nervio frénico, provoca debilidad muscular y, por tanto, reducción de las presiones inspiratorias $(60,61)$. Se describe en el hipotiroidismo mayor relación de síndrome de apnea obstructiva del sueño (SAOS), sobre todo en obesos (62); existe una relación directa entre la gravedad del hipotiroidismo y la presencia de somnolencia diurna y ronquidos, los cuales mejoran con hormona tiroidea $(63,64)$. 
El SEE con frecuencia se observa en pacientes con cáncer de pulmón no microcítico, y se considera también un predictor de mal pronóstico (65).

El exceso de hormonas tiroideas, por las alteraciones electrolíticas que producen (hipopotasemia, hipofosfatemia e hipomagnesemia), pueden cursar con miopatías $(15,66)$. Sin embargo, también puede existir clínica de miopatía en el 70\% de los pacientes hipotiroideos $(67,68)$.

En lo que respecta a la función renal, puede verse alterada en ausencia de hormonas tiroideas. De hecho, en pacientes con aumento de creatinina sérica o descenso en el FG de causa no clara, deberían considerarse en el screening de enfermedad renal crónica (ERC) la determinación de hormonas tiroideas, ya que en caso de detectarse una disminución de hormonas tiroideas, el tratamiento de sustitución con esta hormona podría mejorar la función renal (69-72). El síndrome nefrótico se ha relacionado con el descenso de los niveles de T4 y T3 (73).

Iglesias y cols. estudiaron el papel de las hormonas tiroideas en el fracaso renal agudo (FRA) y detectaron que el $80 \%$ de los pacientes con FRA presentaban alteraciones en las pruebas de función tiroidea, siendo el trastorno más común el SEE (principalmente el síndrome de T3 baja), que se recuperaba espontáneamente a medida que mejoraba la función renal; sin embargo, las alteraciones en las pruebas de función tiroidea no se asociaron con las implicaciones clínicas y pronósticas de los pacientes con FRA (74).

Sin embargo, en pacientes con ERC sin antecedentes de enfermedad tiroidea, la T3 L baja se ha mostrado predictor independiente de mortalidad, tanto en hemodiálisis (75), como en diálisis peritoneal (76). Un estudio reciente ha demostrado que los 
niveles de T3 $L$, en pacientes sometidos a diálisis peritoneal, se asociaban con la rigidez arterial, la calcificación de las arterias coronarias y con la mortalidad (77). Yang y cols. realizaron un estudio en pacientes con ERC y proteinuria, donde observaron que niveles bajos de T3 predecían la mortalidad por todas las causas y por ECV, con independencia de la gravedad de la proteinuria (78).

Respecto al aparato digestivo, existen alteraciones hepáticas por acción directa de las hormonas tiroideas, por la hipoxia del tejido hepático, hepatotoxicidad por drogas, ICC, malnutrición o infecciones intercurrentes (79). En hipertiroideos con enfermedad de Graves, bocio nodular tóxico y tiroiditis silente, se han encontrado alteraciones en las transaminasas (80). También hay descritos casos de pacientes con hipertiroidismo franco y sin enfermedad hepática, que presentaron ictericia y vómitos, a los que se trató con antitiroideos, resolviéndose el cuadro clínico $(81,82)$.

El hipertiroidismo se ha relacionado con disfagia, tanto por compresión por bocio, como por la alteración de la regulación neurohormonal, la cual una vez resuelta, podría revertir la disfagia $(83,84)$. El exceso de hormonas tiroideas incrementa la propagación de velocidad de contracciones esofágicas, produciendo con frecuencia dispepsia crónica (85). Casi un tercio de los pacientes hipertiroideos cursan con gastritis autoinmune (86).

El hipotiroidismo también se acompaña de alteraciones en las funciones hepatobiliares; pueden desarrollar litiasis biliar (sobre todo pacientes con hipotiroidismo subclínico) y esteatosis (87).

En hipotiroideos no severos existe relación con aumento leve de las transaminasas (88). Enfermedades como la cirrosis biliar primaria, hepatitis víricas 
crónicas, virus de la inmunodeficiencia humana (VIH) y la administración de drogas, cursan con aumento de globulina fijadora de tiroxina (TBG) (89).

La ascitis como complicación del mixedema hipotiroideo es poco frecuente; sin embargo, el hipotiroidismo debe incluirse en el diagnóstico diferencial de la ascitis de origen desconocido (90).

El hipotiroidismo severo puede llevar a alteraciones del peristaltismo esofágico, predisponiendo a disfagia, esofagitis y a hernia hiatal, las cuales suelen mejorar con tratamiento con hormona tiroidea $(91,92)$. La hipomotilidad intestinal se relaciona con el estreñimiento, sin embargo, también puede favorecer un incremento del crecimiento bacteriano, simulando un colon irritable, por la distensión abdominal, flatulencia y diarrea (93). También se puede llegar a producir íleo paralítico, megacolon, pseudobstrucción intestinal, distensión intestinal e incluso isquemia mesentérica (86).

La fractura de cadera es un problema común en la población anciana. Algunos estudios han relacionado la disfunción tiroidea con el riesgo de fractura $(94,95)$. De hecho, estudios recientes apuntan los beneficios potenciales del tratamiento con levotiroxina en ancianos con osteoporosis $(96,97)$.

Respecto a la patología psiquiátrica, el hipertiroidismo se suele asociar a síntomas como ansiedad, paranoia e insomnio; son frecuentes el llanto fácil, las alucinaciones visuales o auditivas y la hipomanía, por lo que el hipertiroidismo puede exacerbar la patología psiquiátrica preexistente $(98,99)$.

En relación al SNC, uno de los signos más característicos del hipertiroidismo es el temblor muscular, e incluso puede llevar, en excepcionales ocasiones, a la 
coreoatetosis. También pueden presentar afasia, convulsiones, hemiparesia o parálisis bulbar, que tiende a resolverse tras la normalización de las hormonas tiroideas (98).

En pacientes ancianos con hipertiroidismo puede prevalecer la confusión, la demencia y la pérdida de atención $(20,100)$. En otros casos, se produce enlentecimiento mental, que en ocasiones se confunde con depresión severa. En contraposición, también el hipotiroidismo franco se ha relacionado con somnolencia y deterioro cognitivo (101). Sin embargo, el estudio OCTABAIX, no encuentra relación entre el hipotiroidismo ni hipertiroidismo subclínico y el deterioro cognitivo (102).

EI SEE puede producirse tras horas de una cirugía mayor, donde es frecuente observar en ancianos una disfunción cognitiva que, a su vez, se relaciona con aumento significativo de la morbilidad y mortalidad (103).

No parece haber riesgo aumentado de accidente cerebrovascular agudo (ACVA) en pacientes hipertiroideos, excepto en pacientes con FA permanente; se estima que uno de cada seis pacientes con ACVA tiene FA (18). Por otra parte, un estudio comprobó que una gran proporción de pacientes con ACVA fueron diagnosticados tras un evento con niveles bajos de T3, concluyendo que el síndrome de T3 baja era un predictor independiente de supervivencia (104).

Por tanto, algunos estudios $(3,9,44 ; 105-107)$, pero no todos $(102,108)$ sugieren una relación entre las pruebas de función tiroidea alterada con la morbilidad y la mortalidad en ancianos hospitalizados $(3,39)$. La alteración de la función tiroidea no tratada en las personas mayores se asocia con morbilidad significativa (108-112). 


\subsection{Mortalidad y disfunción tiroidea}

La relación de la disfunción tiroidea con diversos trastornos es conocida desde hace mucho tiempo (1), aunque sólo en los últimos años se han dado a conocer resultados de estudios que relacionan la disfunción tiroidea con la mortalidad. Franklyn y cols. (1998) describieron un incremento de la mortalidad por todas las causas y de la mortalidad cardiovascular, en una cohorte de 7.209 individuos con hipertiroidismo tratados con radioyodo desde 1950 a 1989 (113). El aumento de la mortalidad detectado en este estudio no pudo ser atribuido a una única causa, y los autores lo explicaron a través de un efecto directo del exceso de hormonas tiroideas, una influencia específica del tratamiento con radioyodo, o bien, una influencia del hipotiroidismo que con frecuencia se desarrolla tras el tratamiento con radioyodo. En un estudio posterior, los autores encuentran un $14 \%$ de incremento en la mortalidad de los pacientes hipertiroideos en comparación con la población de referencia (114).

El hipotiroidismo, tras radioyodo y su tratamiento con $\mathrm{T} 4$, se han considerado como posibles factores influyentes o modificadores de la elevación en la tasa de mortalidad de los pacientes hipertiroideos. En una cohorte de 2.668 individuos mayores de 40 años tratados con radioyodo por hipertiroidismo, Franklyn y cols. (2005) ponen de manifiesto que en los individuos que no tomaban T4, la elevación del riesgo de mortalidad persistía, mientras que este riesgo no fue evidente en el grupo de pacientes que tomaban T4 (114). Este hallazgo es muy sugerente de que el desarrollo de un hipotiroidismo franco, tras el tratamiento del hipertiroidismo con radioyodo, es una prueba de curación del hipertiroidismo y, por tanto, se asocia con una mejoría de los efectos adversos del exceso de hormonas tiroideas sobre el sistema cardiovascular. 
Otro hallazgo destacable es el aumento de la mortalidad por todas las causas, en comparación con la población general, en los pacientes que fueron seguidos previamente al inicio de terapia con $\mathrm{T} 4$ o que no requirieron $\mathrm{T} 4$, tanto si presentaban valores de TSH bajos, normales o elevados. Además, los pacientes con concentraciones elevadas de TSH, es decir, con hipotiroidismo subclínico, presentaron un mayor riesgo de mortalidad por cardiopatía isquémica $(\mathrm{Cl})$, en comparación con los sujetos que presentaban una TSH normal (114). Este hallazgo se interpreta a través de una posible relación entre la elevación de TSH y la presencia de dislipemia, aspecto que ha sido descrito por diversos autores.

El estudio CHIANTI (115) relaciona el hipertiroidismo subclínico con la mortalidad por cualquier causa, respecto a aquellos pacientes con función tiroidea normal. Sin embargo, no se encontró asociación con la mortalidad cardiovascular. En consonancia con los resultados del estudio CHIANTI, un importante estudio Australiano (116), también encuentra que los niveles elevados de T4 se relacionan con la mortalidad por cualquier causa, independientemente de los factores de riesgo y comorbilidades médicas.

Parle y cols. realizaron un estudio de base poblacional que analizó los efectos a largo plazo del hipertiroidismo sobre la mortalidad en una cohorte de 1.191 personas de ambos sexos mayores de 60 años. El seguimiento de esta cohorte fue de 10 años y sus resultados indicaron que la mortalidad por todas las causas fue significativamente mayor en los individuos que presentaron concentraciones bajas de TSH (menores de 0,5 $\mathrm{mU} / \mathrm{L}$ ). Las razones de mortalidad estandarizadas (SMR) a los 2, 3, 4 y 5 años fueron, respectivamente de $2,1,2,1,1,7$ y 2,8 . La mortalidad por todas las causas, sin 
embargo, no fue diferente de la esperada a los 10 años de seguimiento. Cuando se analizó la mortalidad por enfermedades circulatorias, se observó también un incremento significativo a los 2 (SMR de 2,1), $3(2,2), 4(1,9)$ y $5(2,0)$ años de seguimiento. En este estudio, los pacientes con TSH elevada (>5,0 mU/L) presentaron unas tasas de mortalidad similares a las encontradas en pacientes eutiroideos (TSH entre 0,5 y $5,0 \mathrm{mU} / \mathrm{L})(105)$.

Los estudios de relación entre el hipotiroidismo y la mortalidad han arrojado resultados variables y no coincidentes con los hallazgos de Franklyn y cols. (114) comentados anteriormente. Las relaciones entre el hipotiroidismo subclínico y la enfermedad aterosclerótica cardiaca y cerebrovascular se estudiaron en un grupo de 2.856 personas de ambos sexos, pertenecientes a una cohorte de supervivientes de la bomba atómica de Nagasaki (117). El hipotiroidismo subclínico se asoció a la $\mathrm{Cl}$ en la población total y en los varones, pero no en las mujeres. El seguimiento de esta cohorte durante 10 años mostró un incremento de la mortalidad por todas las causas en los años 3 a 6 del seguimiento en los varones con hipotiroidismo subclínico, aunque este incremento de la mortalidad no se observó en las mujeres. Por el contrario, en un estudio de base poblacional realizado en una cohorte de 2.799 hombres y mujeres, residentes en Tennessee, no se encontró asociación entre el hipotiroidismo subclínico y la $\mathrm{Cl}$ o la enfermedad arterial periférica (EAP), aunque sí entre el mencionado trastorno hormonal y el riesgo de ICC. Tampoco se observó en este estudio una asociación significativa entre hipotiroidismo subclínico y mortalidad (118).

Un estudio realizado en 403 varones de más de 73 años de edad ha mostrado que las concentraciones séricas de T4 L, dentro del intervalo de normalidad, se 
relacionaron de forma significativa con un incremento de la mortalidad a los 4 años, con un riesgo relativo de 1,27 [intervalo de confianza (IC) al 95\% de 1,01-1-60]. Es decir, las concentraciones bajas de T4 $\mathrm{L}$ se asociaron con una menor mortalidad a los 4 años. Las concentraciones séricas de TSH y de T3 no se relacionaron con la mortalidad en este estudio. Los sujetos con el síndrome de la T3 baja no presentaron un incremento en el riesgo de mortalidad a los 4 años en comparación con sujetos sin este síndrome. Los sujetos con hipertiroidismo subclínico o con hipotiroidismo subclínico no mostraron una mayor mortalidad a los cuatro años que los sujetos eutiroideos, si bien, el número de personas con disfunción tiroidea fue muy escaso. La relación entre la T4 L y la mortalidad fue independiente de la presencia de enfermedad y de parámetros de función física (3).

El estudio de Van den Beld y cols. (3) no confirma los resultados hallados por Parle y cols. (105), y sí parece coincidir en parte con los hallazgos del grupo holandés de Gussekloo y cols. (44). Estos autores encontraron que los niveles bajos de T4 L se asociaban con una mayor supervivencia en una población de hombres y mujeres de edad superior a los 85 años. Estos autores también demostraron que los niveles elevados de TSH se asocian a una menor tasa de mortalidad, y que esta asociación persistió tras ajustar para variables de discapacidad y estado de salud. Los pacientes con niveles anormalmente elevados de TSH y bajos de T4 $\mathrm{L}$ presentaron las menores tasas de mortalidad. Los niveles de TSH anormalmente bajos se asociaron a mayor mortalidad. 
Por tanto, algunos de los estudios de mortalidad $(3,9,44 ; 105-107)$ realizados hasta la fecha, aunque no todos $(108,119)$, sugieren que la disminución de los niveles de TSH y el aumento de los de T4 L se asocian a un incremento de la mortalidad, mientras que la hipofunción tiroidea ligera, caracterizada por una elevación de TSH o la reducción de la T4 L, parecen comportarse como factores que incrementan la supervivencia en personas ancianas $(3,44,107)$. El estudio japonés (117) discrepa con estos resultados, pero la media de edad de los sujetos estudiados fue de sólo 58 años, lo que sugiere que los hallazgos en sujetos ancianos no son extrapolables a poblaciones de otras edades.

Los mecanismos por los que una elevación de TSH o un descenso de T4 pueden asociarse a un incremento de la supervivencia en ancianos no están claramente establecidos. La disminución de la tasa metabólica basal se asocia a una mayor supervivencia en varias especies animales (120), y es posible que una disminución de la tasa metabólica basal también se asocie a una menor supervivencia en humanos.

Las bajas concentraciones séricas de T3 se encuentran entre el 32-62\% de los pacientes mayores hospitalizados (3), y se comportan como un potente predictor de mortalidad durante la hospitalización de pacientes ancianos $(39,121)$. Sin embargo, un estudio muy reciente, realizado en la Universidad de Florencia (3) con 450 ancianos ingresados por enfermedad aguda, relaciona el síndrome de T3 baja con el pronóstico a corto plazo, pero no a largo plazo, aumentando el riesgo de mortalidad intrahospitalaria y no la mortalidad a largo plazo. 
Determinados factores (envejecimiento, fármacos, enfermedades no tiroideas) están relacionados con el pronóstico vital de los pacientes hospitalizados, pero son difíciles de cuantificar y expresar de una forma numérica. Estos factores afectan la secreción de TSH de manera más marcada en los pacientes más graves. Por tanto, cabe preguntarse si la TSH podría ser considerada como un indicador del riesgo de muerte, a corto o medio plazo, en los ancianos hospitalizados por un proceso agudo. Ésta es la principal hipótesis de la presente tesis. La TSH es un parámetro analítico fácilmente cuantificable, económico y asequible en todos los hospitales y tiene una expresión numérica sencilla.

Una encuesta reciente, mostró que una sola medición de la función tiroidea (TSH y T4) no era capaz de predecir la mortalidad total o por causa específica en una cohorte de ancianos durante un periodo de 8 años de seguimiento (9).

En resumen, la prevalencia de disfunción tiroidea en la población general es un problema frecuente; dicha prevalencia aumenta con la edad, siendo la prevalencia en ancianos aproximadamente del 8,5\%. En los ancianos hospitalizados esta prevalencia es mayor, alcanzando cifras del 40,7\%. Existen estudios que han relacionado la disfunción tiroidea con la mortalidad con resultados contradictorios (117): algunos estudios consideran que la disminución de los niveles de TSH y el aumento de los de T4 L se asocian a un incremento de la mortalidad, y otros que la hipofunción tiroidea ligera parece comportarse como factor que incrementa la supervivencia en personas ancianas. 



\section{HIPÓTESIS Y OBJETIVOS}

\subsection{Hipótesis}

Nuestra hipótesis de trabajo fue intentar demostrar que la presencia de disfunción tiroidea al ingreso hospitalario, en el paciente anciano hospitalizado por enfermedad aguda, se asocia con el pronóstico vital a corto y largo plazo.

\subsection{Objetivo principal}

Analizar si una determinación hormonal tiroidea (TSH, T4 L y T3 L) al ingreso se asocia a un peor pronóstico vital, no sólo durante la hospitalización, sino también a largo plazo, así como su relación con la mortalidad global y mortalidad cardiovascular en los pacientes ancianos hospitalizados por un proceso agudo.

\subsection{Objetivo secundario}

Investigar la posible asociación entre las alteraciones de las pruebas de función tiroidea y la comorbilidad en esta población. 



\section{PACIENTES Y MÉTODOS}

\subsection{Características de los pacientes}

Se estudiaron los pacientes mayores de 75 años ingresados en el Servicio de Geriatría del Hospital General de Segovia por enfermedad aguda durante Mayo 2005 Mayo 2006, y fueron seguidos durante un periodo de 7 años. Esta cohorte de pacientes procedía de consultas externas del Servicio de Geriatría o del Servicio de Urgencias, como consecuencia de un proceso agudo intercurrente. Como se muestra en la figura 3, de un grupo inicial de 447 pacientes, se excluyeron 43 pacientes que estaban tomando medicamentos que podían interferir con la función tiroidea (antitiroideos, tiroxina, glucocorticoides, octreotide, dopamina, litio o amiodarona), obteniendo una muestra de estudio final de 404 pacientes.

Figura 3. Distribución de los pacientes según el sexo.

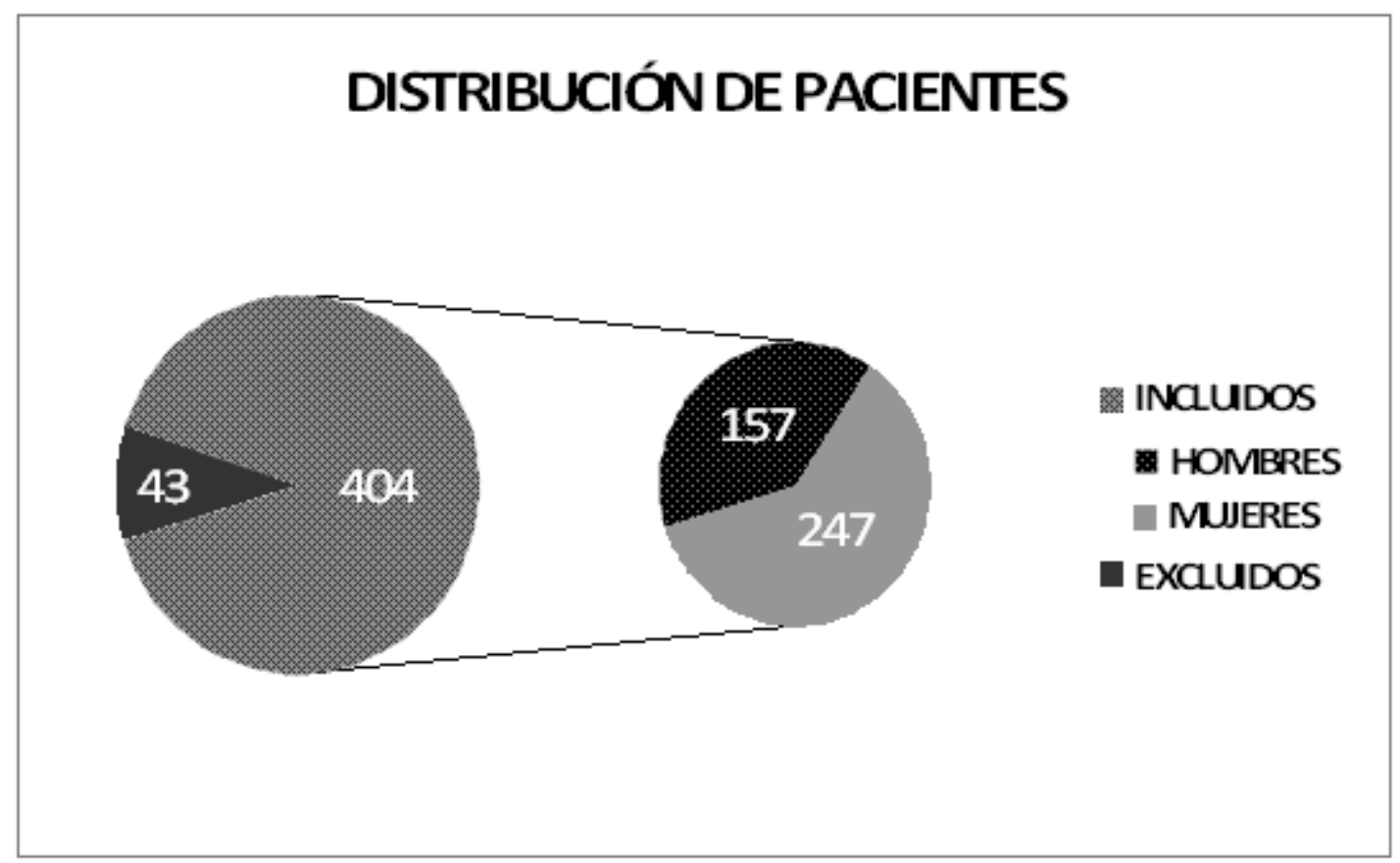



estudiados.

En la tabla 3 se indican las características clínicas y analíticas de los pacientes

Tabla 3. Datos clínicos, analíticos y comorbilidades más frecuentes de los pacientes del estudio. Las cifras indican el número de pacientes (\%) y / o la media \pm desviación estándar para variables de distribución normal y mediana (rango intercuartílico) para datos de distribución no normal.

\begin{tabular}{|c|c|c|c|}
\hline & Mujeres & Varones & Total \\
\hline Número de pacientes (\%) & $247(61,1)$ & $157(38,9)$ & 404 \\
\hline Edad (años) & $86,7 \pm 6,3$ & $84,8 \pm 6,3$ & $85,9 \pm 6,4$ \\
\hline Hipertensión (\%) & $153(61,9)^{*}$ & $67(42,7)$ & $220(54,4)$ \\
\hline Diabetes (\%) & $67(27,1)$ & $34(21,7)$ & $101(25,0)$ \\
\hline Dislipemia (\%) & $37(15,0)$ & $23(14,6)$ & $60(14,8)$ \\
\hline $\begin{array}{l}\text { Enfermedad cardiovascular (\%) } \\
\text { Cardiopatía coronaria } \\
\text { Accidente cerebrovascular } \\
\text { Arteriopatía periférica } \\
\text { Insuficiencia cardiaca congestiva } \\
\text { Arritmia }\end{array}$ & $\begin{array}{l}84(34,0) \\
18(7,3) \\
46(18,6) \\
8(3,2) \\
45(18,2) \\
94(38,0)\end{array}$ & $\begin{array}{l}46(29,3) \\
20(12,7) \\
19(12,1) \\
18(11,5) \\
16(10,2) \\
52(33,1)\end{array}$ & $\begin{array}{l}130(32,2) \\
38(9,4) \\
65(16,1) \\
26(6,4) \\
61(15,1) \\
146(36,1)\end{array}$ \\
\hline Cáncer (\%) & $26(10,5)$ & $28(17,8)$ & $54(13,4)$ \\
\hline $\begin{array}{l}\text { Alteraciones en pruebas de función } \\
\text { tiroidea (\%) } \\
\text { Síndrome eutiroideo enfermo } \\
\text { Hipotiroidismo subclínico } \\
\text { Hipotiroidismo franco } \\
\text { Hipertiroidismo subclínico } \\
\text { Hipertiroidismo franco }\end{array}$ & $\begin{array}{c}180(72,9) \\
151(61,1) \\
16(6,5) \\
2(0,8) \\
5(2,0) \\
6(2,4)\end{array}$ & $\begin{array}{c}115(73,2) \\
100(63,7) \\
7(4,4) \\
2(1,3) \\
3(1,9) \\
3(1,9)\end{array}$ & $\begin{array}{c}295(73,0) \\
251(62,1) \\
23(5,7) \\
4(1,0) \\
8(2,0) \\
9(2,2)\end{array}$ \\
\hline Índice de masa corporal $\left(\mathrm{kg} / \mathrm{m}^{2}\right)$ & $27,4 \pm 6,2$ & $27,2 \pm 3,5$ & $27,3 \pm 5,1$ \\
\hline Presión arterial sistólica (mmHg) & $130(110-150)$ & $130(110-140)$ & $130(110-150)$ \\
\hline Presión arterial diastólica (mmHg) & $70(60-80)$ & $70(60-80)$ & $70(60-80)$ \\
\hline $\mathrm{TSH}(\mathrm{mU} / \mathrm{L})$ & $1,5(0,8-2,6)$ & $1,5(0,8-2,5)$ & $1,5(0,8-2,5)$ \\
\hline T4 L (pmol/L) & $17,2(15,2-19,7)^{*}$ & $16,3(14,3-18,4)$ & $16,9(14,8-19,1)$ \\
\hline T3 L libre (pmol/L) & $3,7 \pm 0,9$ & $3,5 \pm 0,9$ & $3,6 \pm 0,9$ \\
\hline
\end{tabular}

* EL nivel de significación para las comparaciones múltiples se ajustó utilizando la corrección de Bonferroni para: $\mathrm{P}=0,04$. 


\subsection{Metodología}

\subsubsection{Diseño del estudio}

El estudio se divide en dos fases: una primera fase de reclutamiento y una segunda fase de seguimiento de una cohorte de pacientes.

\section{1) Fase de reclutamiento}

Los pacientes fueron reclutados desde Mayo de 2005 a Mayo de 2006; todos los pacientes que ingresaban en el Servicio de Geriatría del Hospital General de Segovia fueron incluidos en el estudio sin importar la causa de hospitalización, aunque se excluyeron aquellos pacientes que tomaban fármacos que alteran la función de la glándula tiroides.

El estudio se efectuó completando un formulario por paciente que incluía datos clínicos y analíticos contemplados en el estudio sobre prevalencia de disfunción tiroidea (39). Se recogieron los siguientes datos demográficos, clínicos y de laboratorio (tabla 3): antecedentes personales de hipertensión arterial, diabetes mellitus y dislipemia; enfermedades cardiovasculares ( $\mathrm{Cl}$, ICC, arritmia, ACVA y EAP) y cáncer; edad, sexo, peso, índice de masa corporal (IMC), presión arterial sistólica y diastólica, diagnóstico principal al alta, ausencia o presencia de bocio y su grado (122), fármacos de uso crónico; situación funcional evaluada según el Índice de Barthel (45) en su versión modificada por Shah y cols. (123) (Anexo 10.2), concentraciones séricas de glucosa, creatinina, colesterol total, triglicéridos; función tiroidea (concentraciones séricas de TSH, T4 L y T3 L) y autoinmunidad tiroidea. 
Los pacientes se clasificaron según el tipo y la gravedad de la disfunción tiroidea en: hipertiroidismo franco, hipertiroidismo subclínico, hipotiroidismo franco, hipotiroidismo subclínico y SEE.

El diagnóstico de hipotiroidismo primario se consideró cuando el paciente presentaba, simultáneamente, concentraciones de T4 L por debajo del límite inferior de la normalidad y concentraciones de TSH superiores al límite superior del rango de referencia de esta hormona. Se consideraron dos grados de hipofunción tiroidea: hipotiroidismo franco, cuando se cumplían los dos criterios analíticos anteriores, e hipotiroidismo subclínico, cuando el paciente presentase elevación de las concentraciones de TSH junto con concentraciones normales de T4 L. El diagnóstico de hipertiroidismo franco quedó establecido ante la presencia de concentraciones de T4 L o de T3 L por encima del límite superior de la normalidad, simultáneamente con concentraciones inhibidas de TSH. La presencia de una concentración de TSH por debajo del límite inferior de la normalidad junto con concentraciones normales de T4 L y de T3 L fue diagnóstico de hipertiroidismo subclínico. El SEE, o síndrome de T3 baja, describe unas alteraciones en las pruebas de función tiroidea consistentes en disminución de T3 L, T4 L normal o ligeramente disminuida y tirotropina (TSH) normal. Estos cambios se interpretan como un mecanismo adaptativo del organismo a la enfermedad, y se producen por descenso de la conversión periférica de T4 a T3 sin que exista enfermedad en la glándula tiroides.

La TSH se consideró la variable principal, tanto para el diagnóstico de la disfunción tiroidea, como para el estudio de la relación entre la función tiroidea y la mortalidad, con excepción de aquellos pacientes en los que se diagnosticó un hipertiroidismo por 
secreción hipofisaria de TSH o un hipotiroidismo hipotirotropo. La autoinmunidad tiroidea se estudió mediante la cuantificación de los niveles de anticuerpos antitiroideos, es decir, anti-peroxidasa tiroidea (anti-TPO) y anti-tiroglobulina (anti-TG).

\section{2) Fase de seguimiento}

Se realizó un estudio observacional prospectivo durante 7 años con los pacientes mayores de 75 años hospitalizados por un proceso agudo, con independencia de sus valores iniciales de TSH. Se analizó la supervivencia intrahospitalaria y el tiempo total de supervivencia; el número de muertes intra y extrahospitalarias; así como las causas de mortalidad total y cardiovascular. Se estableció como fecha final del estudio, para establecer el tiempo de supervivencia en el hospital y el tiempo total de supervivencia, hasta la fecha de censo, el 1 de Enero de 2012 (census date).

Las causas de mortalidad se dividieron en enfermedades circulatorias y otras enfermedades no circulatorias, tal como se muestra en la tabla 4. Dentro de las enfermedades circulatorias, se clasificaron en enfermedades cardiovasculares, cerebrovasculares y otras enfermedades circulatorias. Entre las enfermedades no circulatorias, se clasificaron en neoplasias malignas, enfermedades respiratorias, enfermedades del sistema digestivo, enfermedades del sistema genitourinario, enfermedades endocrinas y metabólicas, enfermedades infecciosas, hematopoyéticas y otras (donde se incluían, enfermedades mentales, enfermedades del sistema nervioso y lesiones). Dentro de las enfermedades cardiovasculares, se clasificaron en enfermedad reumática o hipertensiva, cardiopatía isquémica y enfermedades de la circulación pulmonar y otras enfermedades cardiacas. 
Tabla 4. Causas de mortalidad (enfermedades circulatorias y otras enfermedades no circulatorias).

\begin{tabular}{|c|c|}
\hline 1. Enfermedades circulatorias & $\begin{array}{l}\text { 1.1. Enfermedades cardiovasculares } \\
\text { 1.1.1. Enfermedad reumática o hipertensiva } \\
\text { 1.1.2. Cardiopatía isquémica y enfermedades } \\
\text { de la circulación pulmonar } \\
\text { 1.1.3. Otras enfermedades cardiacas } \\
\text { 1.2. Enfermedades cerebrovasculares } \\
\text { 1.3. Otras enfermedades circulatorias }\end{array}$ \\
\hline $\begin{array}{l}\text { 2. Otras enfermedades no } \\
\text { circulatorias }\end{array}$ & $\begin{array}{l}\text { 2.1. Neoplasias malignas } \\
\text { 2.2. Enfermedades respiratorias } \\
\text { 2.3. Enfermedades del sistema digestivo } \\
\text { 2.4. Enfermedades del sistema genitourinario } \\
\text { 2.5. Enfermedades endocrinas y metabólicas } \\
\text { 2.6. Enfermedades infecciosas } \\
\text { 2.7. Enfermedades hematopoyéticas } \\
\text { 2.8. Otras causas de enfermedad }\end{array}$ \\
\hline
\end{tabular}

\subsubsection{Análisis hormonal}

Los datos obtenidos con las determinaciones de hormonas tiroideas (T4 L y T3 L) y de TSH realizadas a todos los pacientes, se emplearon para clasificar a todos los participantes como eutiroideos, o bien, como portadores de alguna disfunción tiroidea. Estas determinaciones se realizaron de forma simultánea a las exploraciones 
analíticas habituales para el diagnóstico y seguimiento de los pacientes ingresados en el Servicio de Geriatría del Hospital General de Segovia. Se obtuvieron muestras de sangre en ayunas (entre las 8:30 y 9:00 h de la mañana) de una vena antecubital para las cuantificaciones hormonales en el primer día del ingreso.

La medida de TSH, T4 L y T3 L se realizó mediante un inmunoensayo de electroquimionuminiscencia "ECLIA" en un analizador E 170 (Roche Diagnostics, Manheim, Alemania). Los máximos coeficientes de variación intraensayo e interensayo fueron de $1,35 \%$ y $1,16 \%$ para TSH; $2,04 \%$ y $3,89 \%$ para T4 L; y $2,87 \%$ y $10,17 \%$ para T3 L. La sensibilidad del ensayo es de 0,005 $\mathrm{mU} / \mathrm{L}, 0,3 \mathrm{pmol} / \mathrm{L}$ y 0,4 pmol/L, respectivamente. Los valores de referencia fueron: TSH (0,4-5,0 mU/L); T4 L (11-23) pmol/L y T3 L $(3,09-6,08)$ pmol/L.

\subsection{Análisis estadístico}

Para las variables cuantitativas, los resultados fueron expresados como una media \pm DS para los datos normalmente distribuidos, y como una mediana (rango intercuartílico) para los datos no paramétricos. La normalidad de la distribución de los datos se evaluó mediante el test Kolmogorov-Smirnov. Las variables categóricas se describen como porcentajes. Para la comparación de medias entre dos grupos de sujetos se utilizó la t-Student para los datos de distribución normal y el test MannWhitney para datos no paramétricos. Para la comparación de dos o más grupos independientes unidireccionales, se utilizaron las pruebas de ANOVA y Kruskal-Wallis para datos paramétricos y no paramétricos, respectivamente. Para las comparaciones categóricas se utilizó la prueba de $\chi^{2}$ o la prueba exacta de Fisher. La corrección de Bonferroni para el nivel alfa se aplica cuando se realizaron pruebas con múltiples 
comparaciones. El tiempo de supervivencia fue estimado por las curvas de supervivencia de Kaplan-Meier con la prueba de rango logarítmico utilizado para comparar. Se usaron modelos de regresión de Cox univariante y multivariante para evaluar los efectos independientes de distintas variables cuantitativas (edad, TSH, T4 L y T3 L) y cualitativas (sexo, hipertensión, diabetes mellitus, dislipemia, ECV y cáncer) sobre el riesgo de muerte. Se calcularon las razones de riesgo (hazard ratios, HR), con IC del $95 \%$ para todas las causas de mortalidad y mortalidad cardiovascular. Los pacientes fueron clasificados en tertiles según los niveles de TSH, T4 L y T3 L obtenidos de tres grupos aproximadamente similares en base a los datos analizados. Este análisis implica una posible parcialidad o falta de generalización de estos tertiles en otros grupos de pacientes. Las diferencias se consideraron significativas cuando $P<0,05$.

\subsection{Aspectos éticos}

Este estudio fue aprobado por el Comité de Ética local de Segovia y todos los pacientes y/o sus familiares firmaron el consentimiento informado antes de la participación en el estudio. El presente estudio no añade ninguna intervención más, exceptuando una llamada telefónica/carta a partir del 1 de enero de 2012 para el conocimiento del estado vital del paciente. No se consideró necesario realizar nueva hoja de consentimiento informado, ni otro documento de información al paciente para la realización de esta llamada/carta, o para la investigación en el centro de Atención Primaria de la causa del fallecimiento, en su caso. 



\section{RESULTADOS}

\subsection{Pruebas de función tiroidea y morbilidad}

Las pruebas de función tiroidea se encontraban alteradas en la mayoría de los pacientes (73\%); el SEE fue la alteración más común (251 pacientes, 62,1\%); seguido del hipotiroidismo subclínico (23 pacientes, 5,7\%), hipertiroidismo clínico (9 pacientes, 2,2\%); hipertiroidismo subclínico (8 pacientes, $2,0 \%$ ) y el hipotiroidismo clínico (4 pacientes, 1,0\%), tal como se muestra en la figura 4.

Figura 4. Resultados de la función tiroidea en nuestros pacientes.

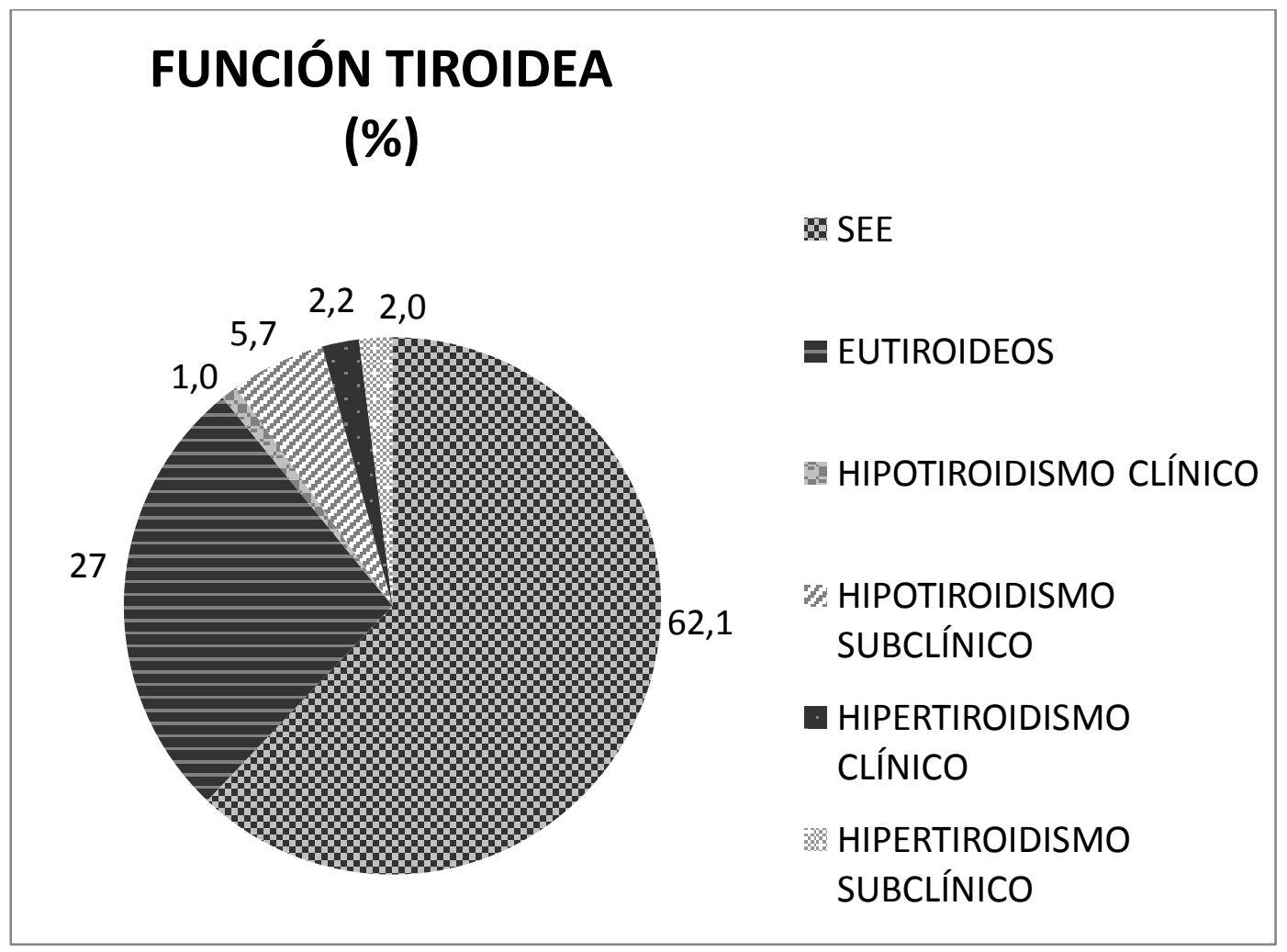


Las comorbilidades más prevalentes se muestran en la tabla 3. La presencia de diabetes, dislipemia, ECV y cáncer no tenían concentraciones séricas significativamente diferentes de TSH, T4 L y T3 L. En la figura 5 se puede comprobar que, sólo los pacientes hipertensos, mostraron unos niveles de T4 L sérica significativamente más elevados respecto a pacientes no hipertensos.

Figura 5. Niveles de T4 L en pacientes hipertensos frente a no hipertensos.

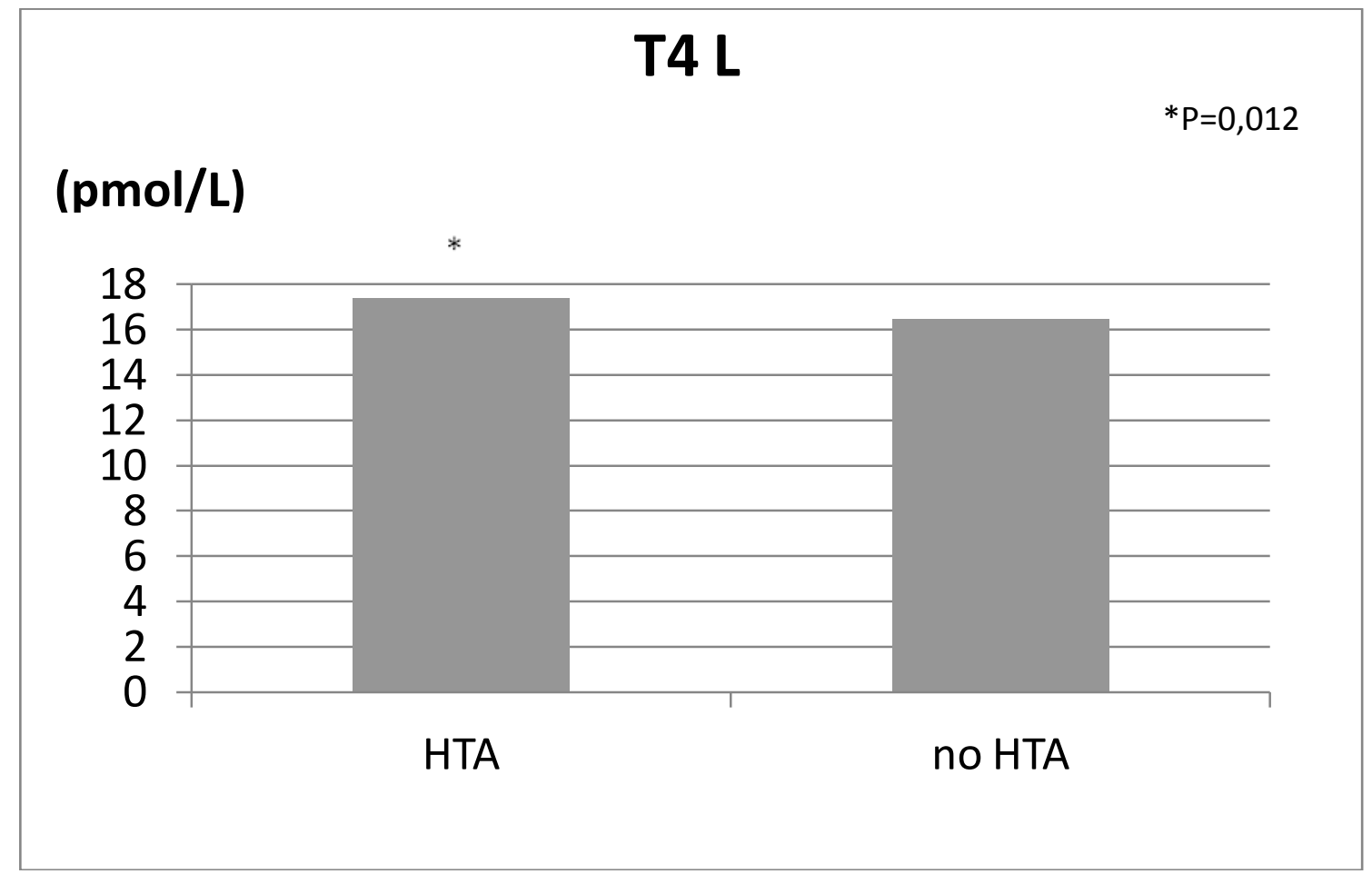

HTA: hipertensión arterial.

Las principales causas de ingreso hospitalario se muestran en la figura 6 y fueron: ICC (77 pacientes, 19,1\%), ACVA (64 pacientes, 15,8\%), infección de vías respiratorias (54 pacientes, 13,4\%), hemorragia digestiva aguda (HDA) (25 pacientes, 6,2\%), Cl (23 pacientes, 5,7\%), exacerbación de enfermedad pulmonar obstructiva crónica (23 pacientes, 5,7\%), cáncer (14 pacientes, 3,5\%), sepsis (11 pacientes, 2,7\%), 
infección del tracto urinario (11 pacientes, 2,7\%), anemia a estudio (7 pacientes, 1,7\%), síncope (7 pacientes, 1,7\%), gastroenteritis aguda (7 pacientes, 1,7\%), síndrome confusional agudo ( 6 pacientes, 1,5\%), bradicardia (6 pacientes, 1,5\%), celulitis (5 pacientes, $1,2 \%$ ), pancreatitis ( 3 pacientes, $0,7 \%$ ) y otras causas (61 pacientes, $15,1 \%$ ). No se encontraron diferencias significativas en la TSH y T4 L entre estos grupos.

Figura 6. Principales causas de ingreso hospitalario.

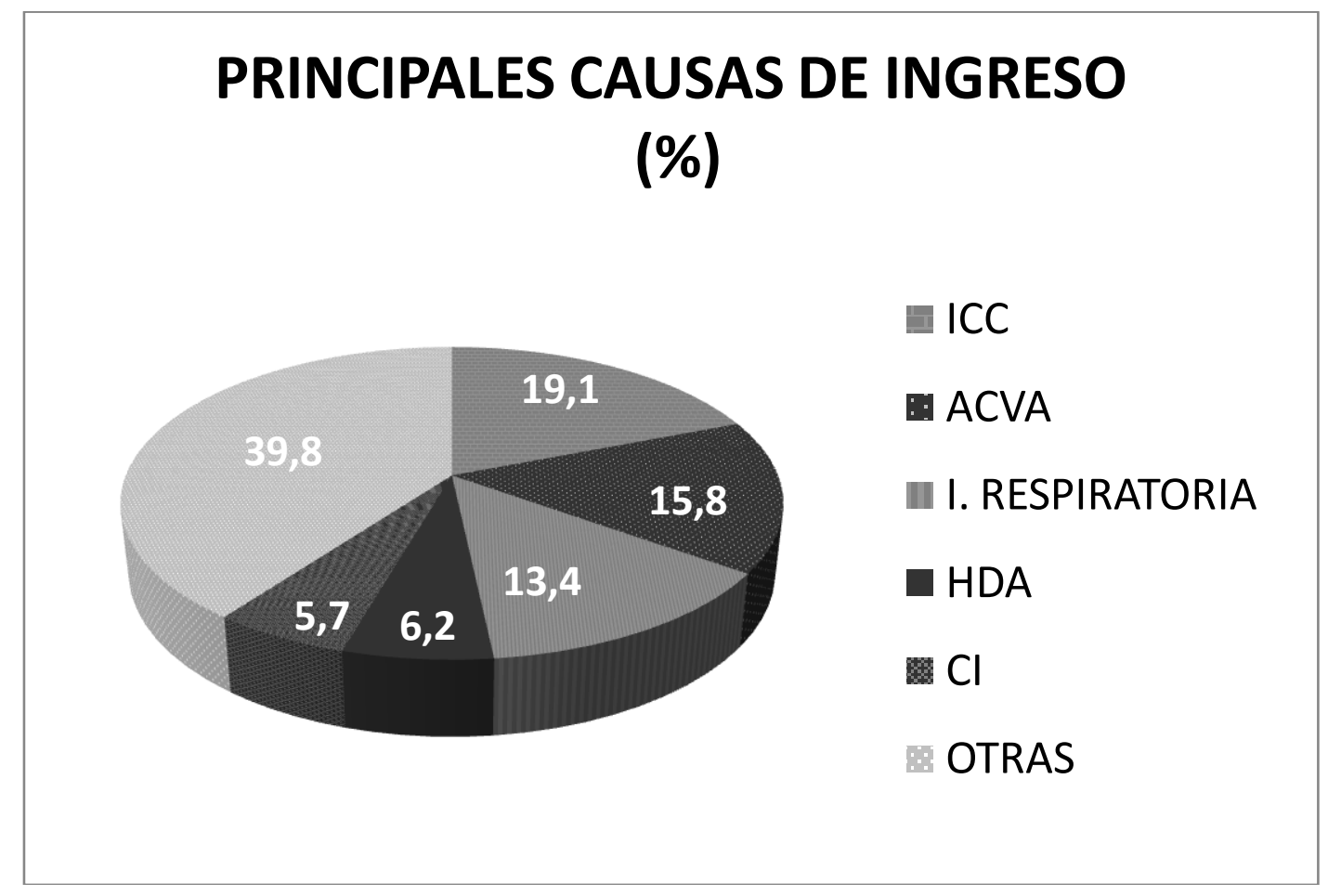

ICC: insuficiencia cardiaca congestiva; ACVA: accidente cerebrovascular agudo; I. RESPIRATORIA: infección respiratoria; HDA: hemorragia digestiva aguda; $\mathrm{Cl}$ : cardiopatía isquémica.

La figura 7 muestra que los pacientes con sepsis tenían unos niveles de T3 L significativamente más bajos $(2,7 \pm 0,8 \mathrm{pmol} / \mathrm{L})$ respecto a los encontrados en pacientes con ACVA $(3,9 \pm 1,0 \mathrm{pmol} / \mathrm{L}, \mathrm{P}=0,002)$ y $\mathrm{Cl}(3,8 \pm 0,9 \mathrm{pmol} / \mathrm{L}, \mathrm{P}=0,001)$. 
Figura 7. Niveles de T3 L en determinadas causas de ingreso

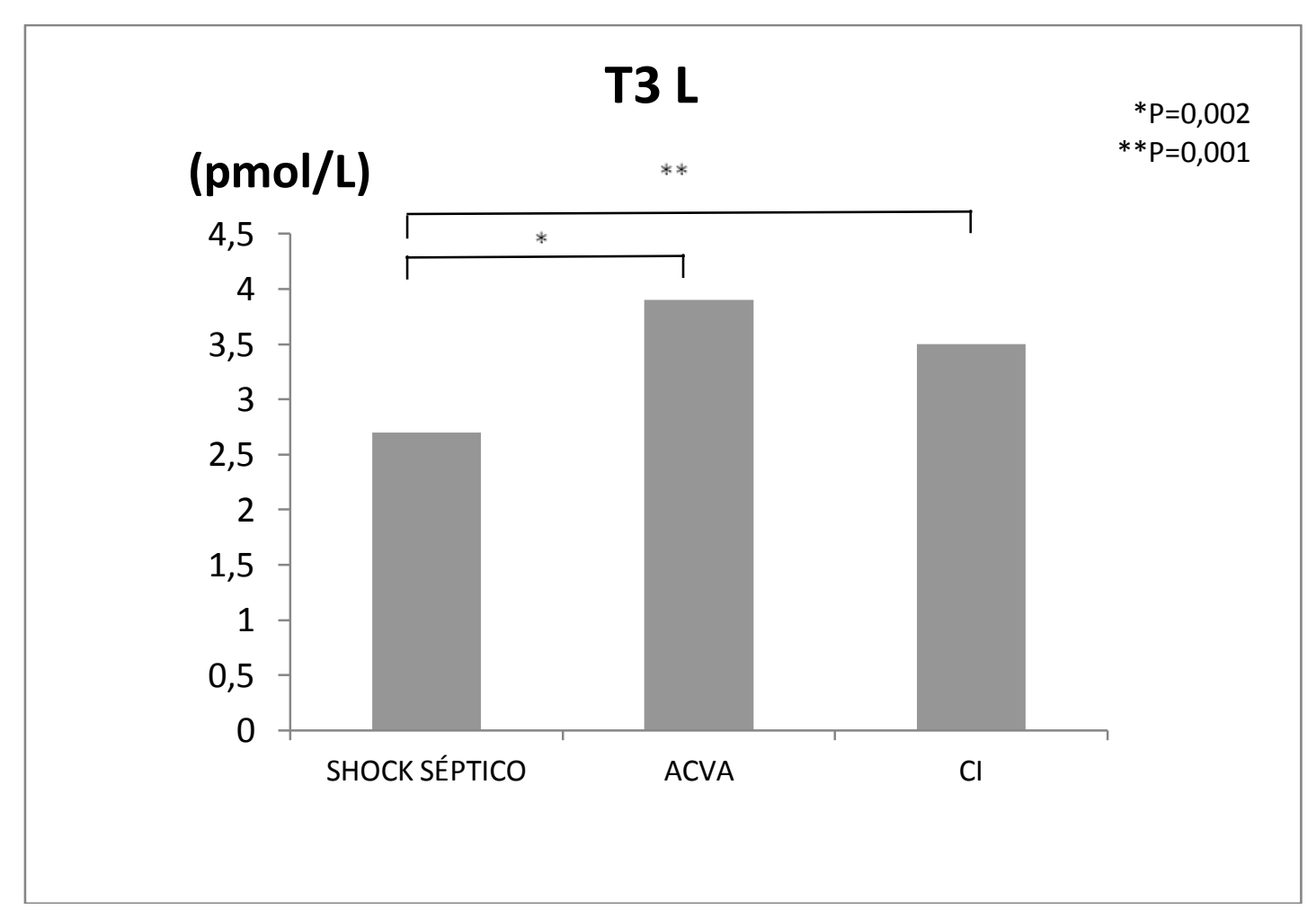

ACVA: accidente cerebrovascular agudo; Cl: cardiopatía isquémica o enfermedad coronaria.

\subsection{Pruebas de función tiroidea y mortalidad}

Durante el estudio, $323(80 \%)$ pacientes fallecieron, tal como se muestra en la figura 8, [tiempo medio de supervivencia 9 meses (rango intercuartílico 1-31 meses); $61(15,1 \%)$ murieron durante la hospitalización]. 
Figura 8. Estado vital de los pacientes el 1 de enero de 2012 (al finalizar la recogida de datos).

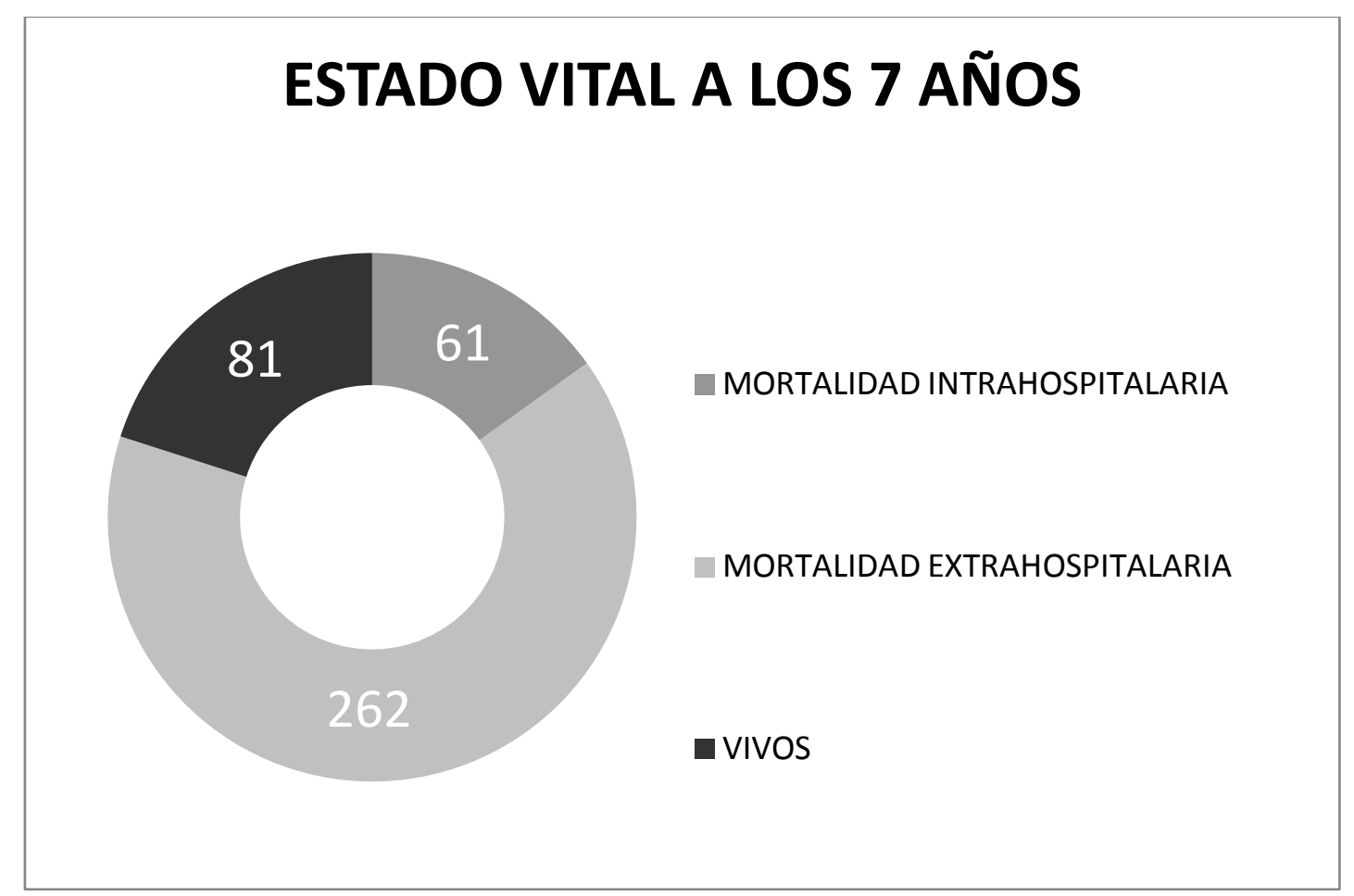

La distribución de los pacientes, según los valores de referencia de la glándula tiroides en relación con el estado vital y el momento de la defunción, se muestran en la tabla 5. 
Tabla 5. Distribución de los pacientes de acuerdo a los valores de referencia de los parámetros de la glándula tiroidea en relación con su estado vital. Las cifras indican el número de pacientes (\%).

\begin{tabular}{|c|c|c|c|c|c|c|c|c|c|c|}
\hline & \multicolumn{3}{|c|}{$\begin{array}{l}\text { Fallecidos en el hospital } \\
\qquad n=61\end{array}$} & \multicolumn{3}{|c|}{$\begin{array}{l}\text { Fallecidos tras el alta } \\
\qquad n=262\end{array}$} & \multicolumn{3}{|c|}{$\begin{array}{c}\text { Supervivientes } \\
\qquad n=81\end{array}$} & \multirow[b]{2}{*}{$P$} \\
\hline & Bajo & Normal & Alto & Bajo & Normal & Alto & Bajo & Normal & Alto & \\
\hline TSH & $\begin{array}{c}7 \\
(11,5 \%)\end{array}$ & $\begin{array}{c}52 \\
(85,2 \%)\end{array}$ & $\begin{array}{c}2 \\
(3,3 \%)\end{array}$ & $\begin{array}{c}24 \\
(9,2 \%)\end{array}$ & $\begin{array}{c}221 \\
(84,4 \%)\end{array}$ & $\begin{array}{c}17 \\
(6,5 \%)\end{array}$ & $\begin{array}{c}1 \\
(1,2 \%)\end{array}$ & $\begin{array}{c}72 \\
(88,9 \%)\end{array}$ & $\begin{array}{c}8 \\
(9,9 \%)\end{array}$ & 0,007 \\
\hline T4 L & $\begin{array}{c}3 \\
(4,9 \%)\end{array}$ & $\begin{array}{c}57 \\
(93,4 \%)\end{array}$ & $\begin{array}{c}1 \\
(1,6 \%)\end{array}$ & $\begin{array}{c}7 \\
(2,7 \%)\end{array}$ & $\begin{array}{c}238 \\
(90,8 \%)\end{array}$ & $\begin{array}{c}17 \\
(6,5 \%)\end{array}$ & $\begin{array}{c}3 \\
(3,7 \%)\end{array}$ & $\begin{array}{c}74 \\
(91,4 \%)\end{array}$ & $\begin{array}{c}4 \\
(4,9 \%)\end{array}$ & NS \\
\hline T3 L & $\begin{array}{c}52 \\
(85,2 \%)\end{array}$ & $\begin{array}{c}9 \\
(14,8 \%)\end{array}$ & 0 & $\begin{array}{c}170 \\
(64,9 \%)\end{array}$ & $\begin{array}{c}91 \\
(34,7 \%)\end{array}$ & $\begin{array}{c}1 \\
(0,4 \%)\end{array}$ & $\begin{array}{c}37 \\
(45,7 \%)\end{array}$ & $\begin{array}{c}44 \\
(54,3 \%)\end{array}$ & 0 & $<0,001$ \\
\hline
\end{tabular}

Rango normal: TSH 0,4-5,0 mU/L; T4 L 11-23 pmol/L y T3 L 3,9-6,8 pmol/L. 
Como se muestra la figura 9, el porcentaje de pacientes con T3 baja fue significativamente mayor en el grupo de pacientes que fallecieron en el hospital, en comparación con los que fallecieron tras el alta. De los 144 pacientes que tenían T3 L en rango normal, sólo 9 de ellos $(6,2 \%)$ fallecieron durante la hospitalización, por lo que los resultados dan un alto valor predictivo de supervivencia.

Figura 9. Alto valor predictivo de supervivencia de T3 L.

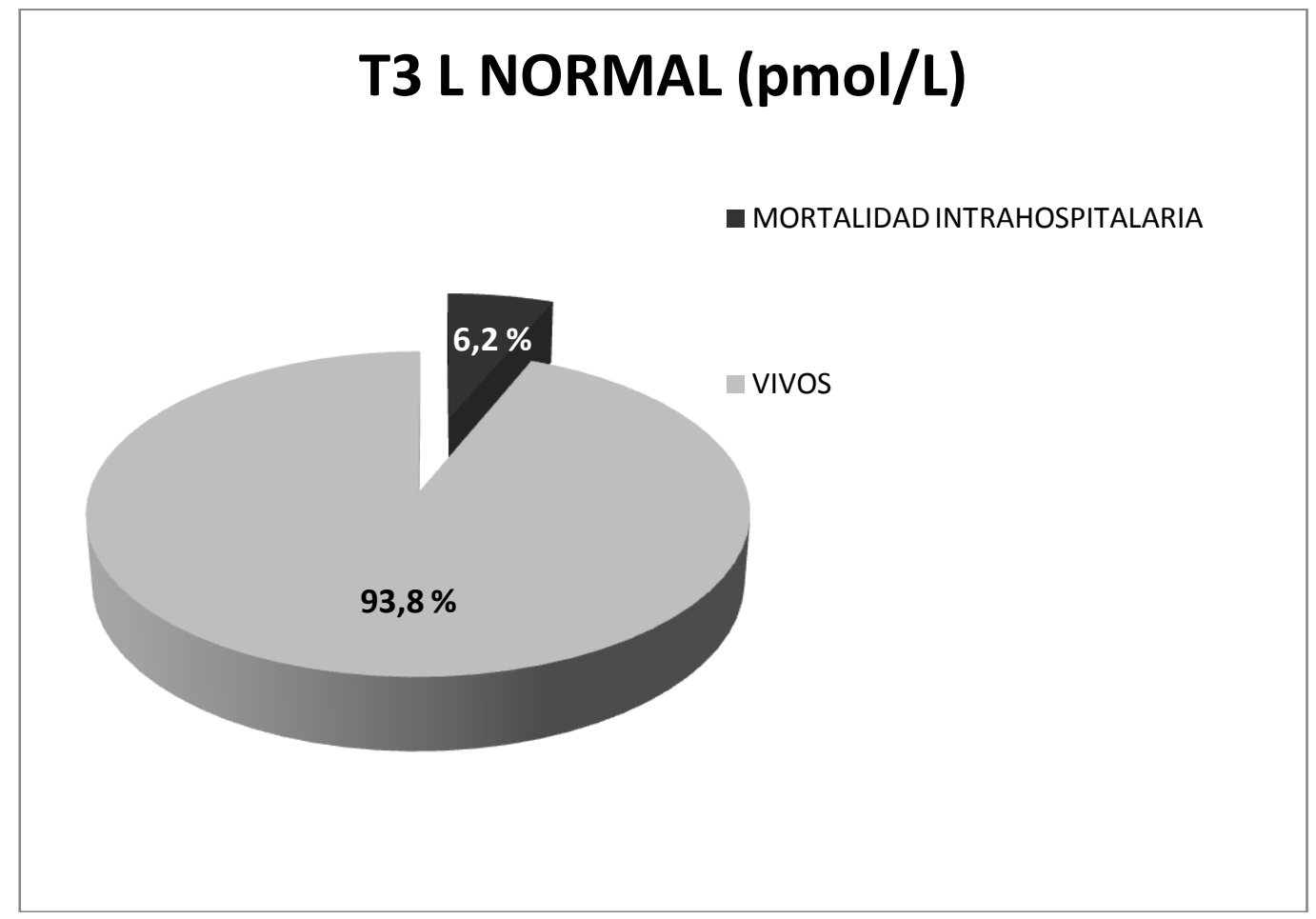

Los pacientes que fallecieron tenían significativamente más edad y unos niveles menores de T3 $L$ frente a los pacientes que sobrevivieron, tal como se muestra en la tabla 6. 
Tabla 6. Datos clínicos y analíticos de los pacientes del estudio a la entrada en función de su estado vital al final del estudio. Las cifras indican el número de pacientes (\%) y/o de la media \pm desviación estándar para datos distribuidos normalmente y mediana (rango intercuartílico) para datos de distribución no normal.

\begin{tabular}{|c|c|c|c|}
\hline & Vivos & Fallecidos & $P$ \\
\hline Número de pacientes (\%) & $81(20)$ & $323(80)$ & \\
\hline Edad (años) & $84,0 \pm 6,8$ & $86,4 \pm 6,2$ & 0,002 \\
\hline Hipertensión (\%) & $48(59,3)$ & $172(53,2)$ & NS \\
\hline Diabetes (\%) & $15(18,5)$ & $86(26,6)$ & NS \\
\hline Dislipemia (\%) & $11(13,6)$ & $49(15,1)$ & NS \\
\hline $\begin{array}{l}\text { Enfermedad cardiovascular } \\
\text { (\%) } \\
\text { Cardiopatía coronaria } \\
\text { Accidente cerebrovascular } \\
\text { Arteriopatía periférica } \\
\text { Insuf. cardiaca congestiva }\end{array}$ & $\begin{array}{c}27(33,3) \\
5(6,2) \\
16(19,7) \\
2(2,5) \\
10(12,3) \\
\end{array}$ & $\begin{array}{c}103(31,9) \\
33(10,2) \\
49(15,2) \\
24(7,4) \\
51(15,8) \\
\end{array}$ & NS \\
\hline Cáncer (\%) & $8(9,9)$ & $46(14,2)$ & NS \\
\hline $\begin{array}{l}\text { Índice de masa corporal } \\
\left(\mathrm{kg} / \mathrm{m}^{2}\right)\end{array}$ & $27,3 \pm 6,0$ & $27,4 \pm 5,0$ & NS \\
\hline $\begin{array}{l}\text { Presión arterial sistólica } \\
(\mathrm{mmHg})\end{array}$ & $135(120-150)$ & $130(110-150)$ & NS \\
\hline $\begin{array}{l}\text { Presión arterial diastólica } \\
(\mathrm{mmHg})\end{array}$ & $75(70-80)$ & $70(60-80)$ & NS \\
\hline $\mathrm{TSH}(\mathrm{mU} / \mathrm{L})$ & $1,8(0,9-2,8)$ & $1,5(0,8-2,4)$ & NS \\
\hline T4 L (pmol/L) & $17,2(14,9-19,3)$ & $16,8(14,8-19,0)$ & NS \\
\hline T3 L (pmol/L) & $4,0 \pm 0,9$ & $3,5 \pm 0,9$ & $<0,001$ \\
\hline
\end{tabular}

* El nivel de significación para las comparaciones múltiples se ajustó utilizando la corrección de Bonferroni para: $P=0,04$. 
La presencia de alteraciones en las pruebas de función tiroidea se asoció positivamente con la mortalidad $(P=0,001)$. Entre los pacientes que fallecieron, TSH $[1,2(0,7-2,2) \mathrm{mU} / \mathrm{L}$ vs $1,6(0,9-2,6) \mathrm{mU} / \mathrm{L}, \mathrm{P}=0,047]$ y $\mathrm{T} 3 \mathrm{~L}(3,2 \pm 0,8$ vs $3,7 \pm 0,9 \mathrm{pmol} / \mathrm{L}$, $P<0,001)$, fueron menores en los que lo hicieron durante la hospitalización en comparación con aquellos que sobrevivieron a la hospitalización, tal como se muestra la figura 10. No se encontraron diferencias significativas en T4 L.

Figura 10. Concentraciones séricas de TSH y T3 $\mathrm{L}$ en los pacientes que fallecieron durante el ingreso y en aquellos que lo hicieron tras el alta hospitalaria.

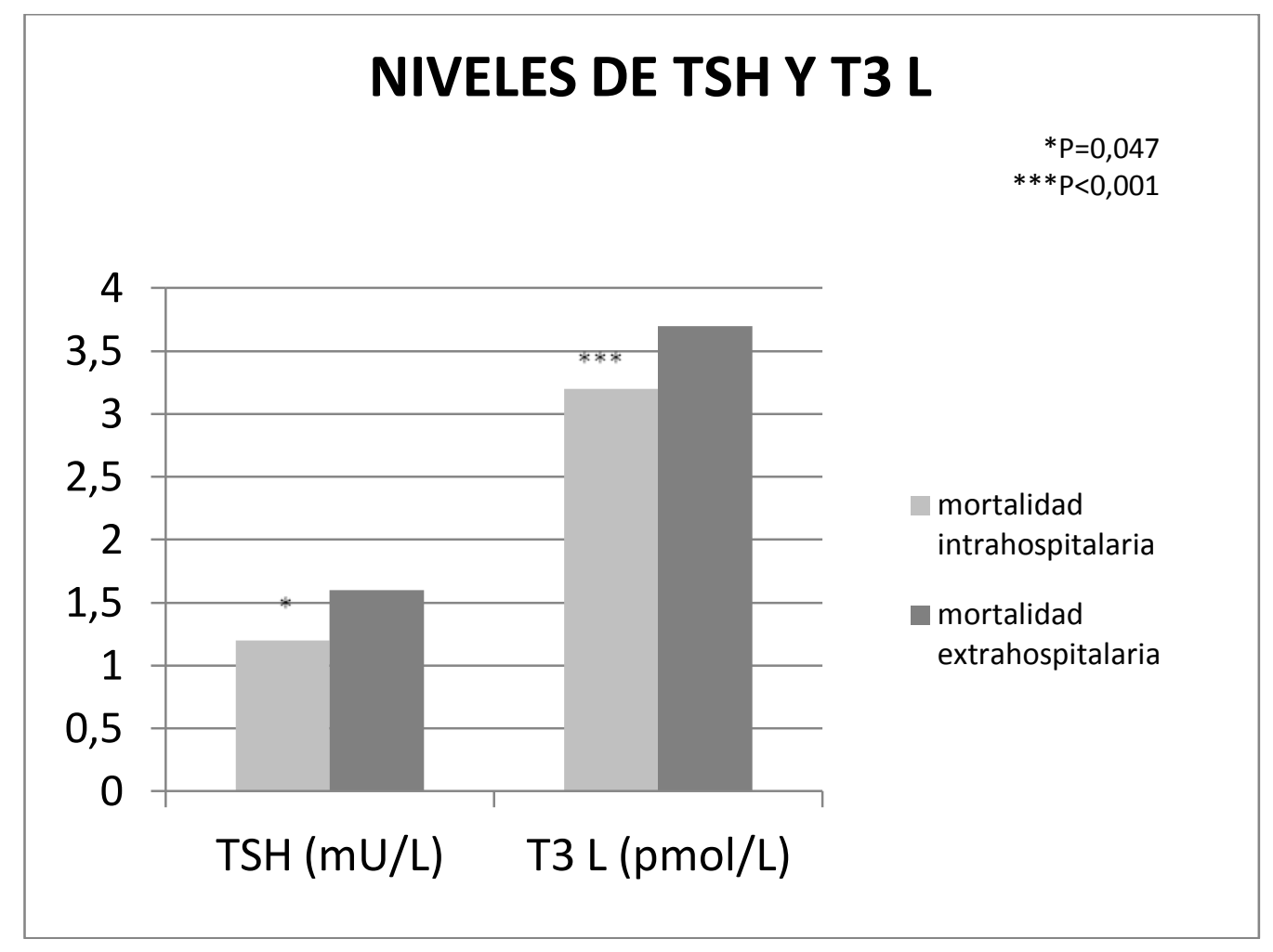

De los 323 pacientes que murieron, sólo se pudo registrar la causa de muerte en 202 pacientes (62,5\%). La ECV fue la principal causa de mortalidad (61 pacientes; 30,2\%). La figura 11 muestra las causas de muerte más relevantes. No se encontró ninguna diferencia significativa en la clínica, analítica, ni en las pruebas de función 
tiroidea entre los pacientes que fallecieron de ECV y por otras causas. No hubo diferencias significativas en los niveles de TSH, T3 L, T4 $L$ entre los pacientes que murieron a causa de la ECV durante la hospitalización y los que lo hicieron después del alta hospitalaria.

Figura 11. Causas de mortalidad más relevantes en la población estudiada.

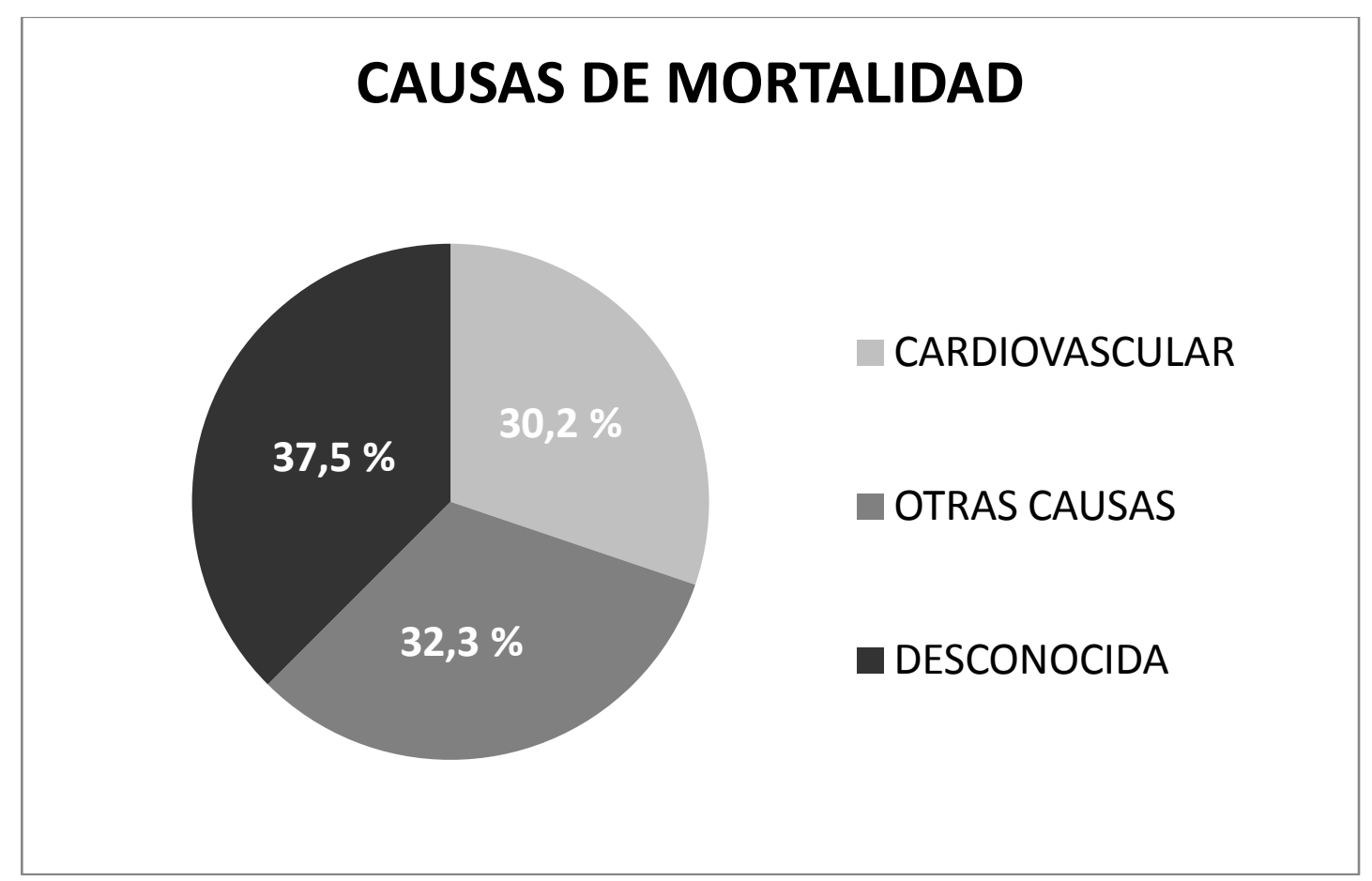

El análisis de Kaplan-Meier mostró un tiempo de supervivencia (mediana) para todas las causas de mortalidad de 3,0 (IC $95 \%, 1,1-4,9), 13,0(6,1-19,8)$ y $19,0(12,1-$ $13,3)$ meses para los pacientes pertenecientes al primer ( $T 3 L \leq 3,18 \mathrm{pmol} / \mathrm{L})$, segundo $(3,18>\mathrm{T} 3 \mathrm{~L} \leq 3,96 \mathrm{pmol} / \mathrm{L})$ y tercer $(\mathrm{T} 3 \mathrm{~L}>3,96 \mathrm{pmol} / \mathrm{L})$ tertil de $\mathrm{T} 3 \mathrm{~L}$, respectivamente $(\mathrm{P}<0,001)$ como se puede observar en la tabla 7. Al considerar la TSH, el tiempo de supervivencia medio de todas las causas de mortalidad fue 3,0 (IC 95\%, 0,6-5,4), 17,0 $(9,9-24,1)$ y $12,0(5,7-18,3)$ meses para los pacientes pertenecientes al primer (TSH $\leq$ 
$1,06 \mathrm{mU} / \mathrm{L})$, segundo $(1,06>\mathrm{TSH} \leq 2,09 \mathrm{mU} / \mathrm{L})$ y tercer $(\mathrm{TSH}>2,09 \mathrm{mU} / \mathrm{L})$ tertil de TSH, respectivamente $(P=0,006)$. De la misma manera, el tiempo de supervivencia medio de todas las causas de la mortalidad fue $6,0(3,6-8,4), 19,0(12,8-25,1)$ y $11,0(6,6-15,4)$ meses para los pacientes pertenecientes al primer ( $T 4 \mathrm{~L} \leq 15,4 \mathrm{pmol} / \mathrm{L}$ ), segundo (15,4> T4 $\mathrm{L} \leq 18,2 \mathrm{pmol} / \mathrm{L}$ ) y tercer (T4 $\mathrm{L}>18,2 \mathrm{pmol} / \mathrm{L}$ ) tertil de $\mathrm{T} 4 \mathrm{~L}$, respectivamente $(P=0,004)$. Hallazgos similares para TSH (prueba de rango logarítmico $6,4, P=0,041$ ) y T3 $\mathrm{L}$ (prueba de rango logarítmico 25,6, $\mathrm{P}<0,001$ ), fueron encontrados al analizar la mortalidad debido a enfermedades cardiovasculares. En la figura 12 se puede ver que el análisis de la supervivencia en relación con los tertiles de T4 L no mostró diferencias significativas en este grupo de pacientes.

Tabla 7. Supervivencia en meses (mediana) según tertiles de TSH, T4 L y T3 L para todos los casos.

\begin{tabular}{|c|c|c|c|}
\hline & T3 L (pmol/L) & T4 L (pmol/L) & TSH (mU/L) \\
\hline & & & \\
Primer tertil & $\leq 3,18$ & $\leq 15,4$ & $\leq 1,06$ \\
Meses & 3,0 & 6,0 & 3,0 \\
& & & \\
Segundo tertil & $3,19-3,96$ & $15,5-18,2$ & $1,07-2,09$ \\
Meses & 13,0 & 19,0 & 17,0 \\
& & & $>2,09$ \\
& & & 12,0 \\
Tercer tertil & 19,0 & 11,0 & \\
Meses & & & \\
\hline
\end{tabular}


Figura 12. Análisis de supervivencia de Kaplan-Meier para todas las causas de mortalidad (izquierda; $n=404$ ) y mortalidad cardiovascular (derecha; $n=283$ ), en los pacientes ancianos ingresados por enfermedad aguda, estratificado según tertiles de TSH, T4 L y T3 L.

Todas las causas de mortalidad
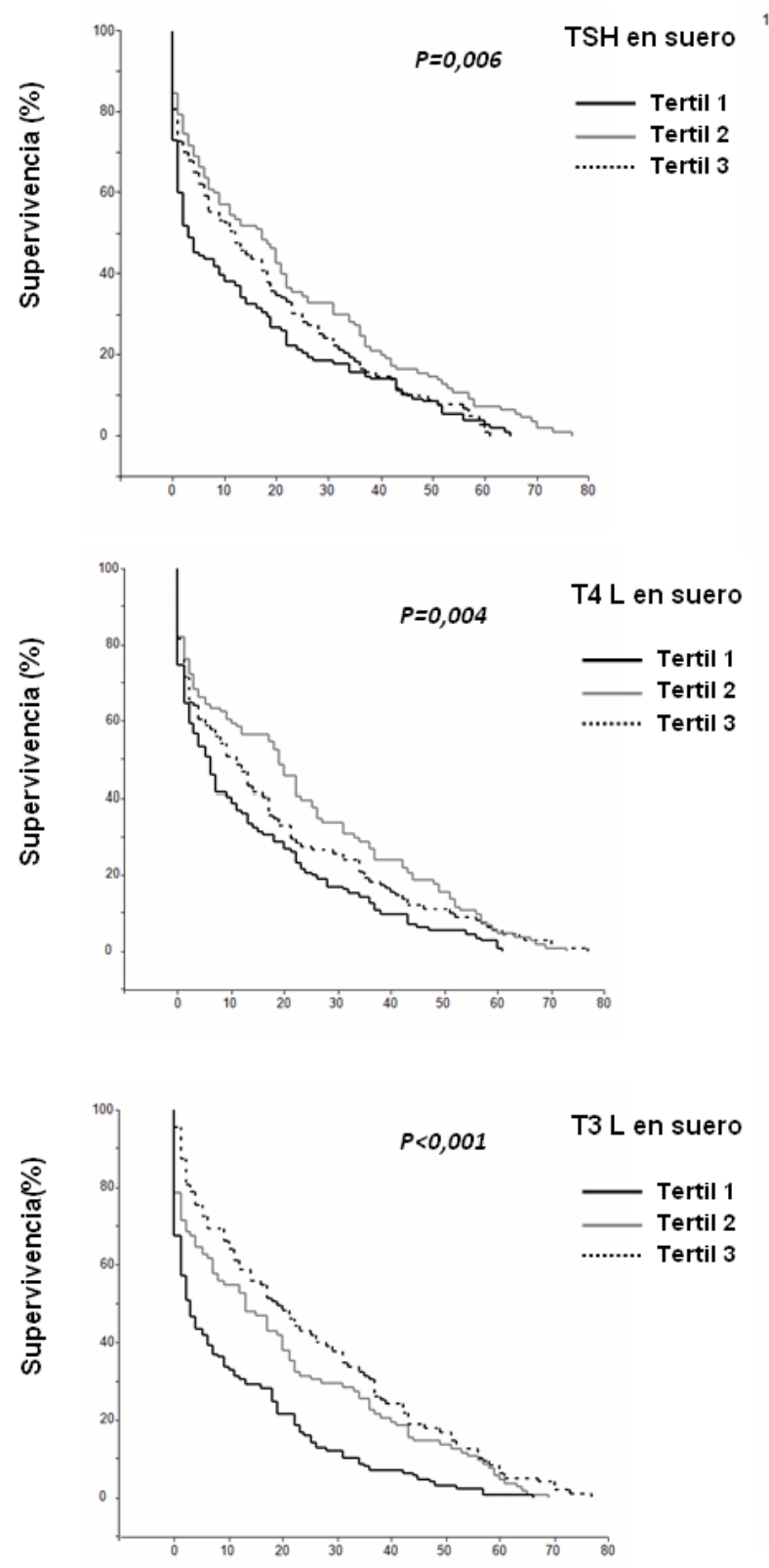

Tiempo de seguimiento (meses)
Mortalidad CV
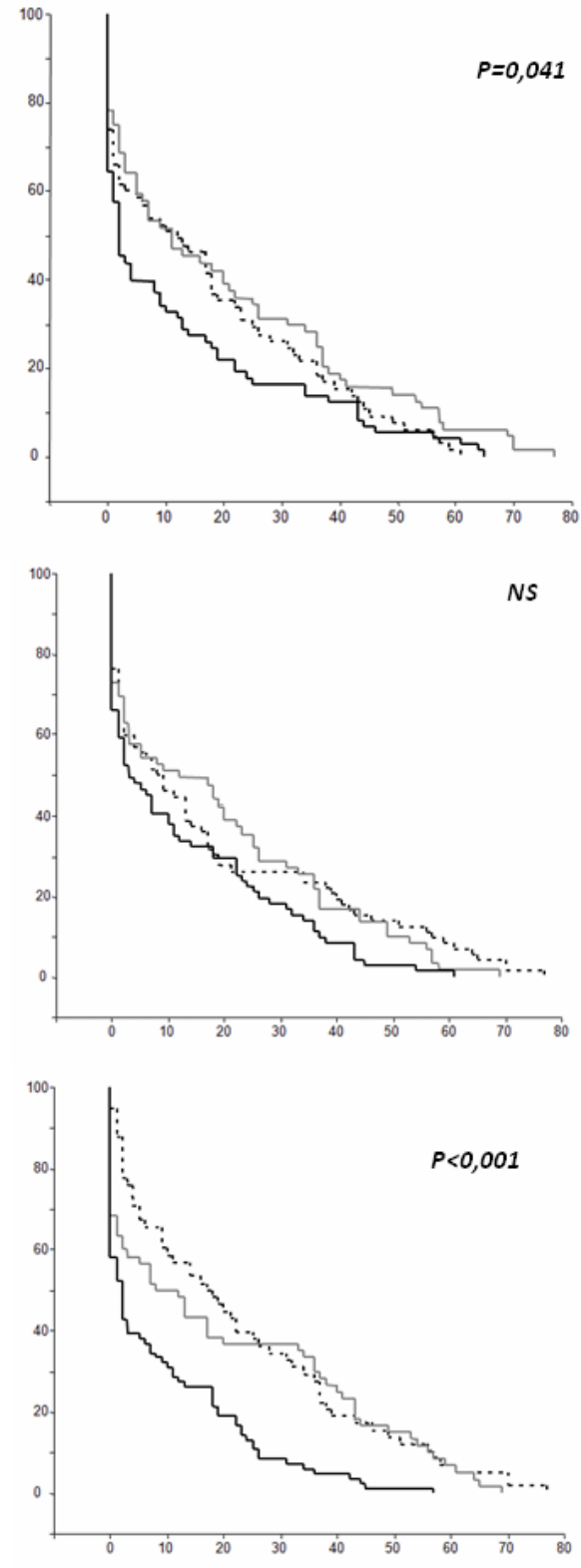

Tiempo de seguimiento (meses) 
En la tabla 8, se puede comprobar que únicamente la edad (HR 1,03; 1,01-1,05, $P=0,001)$ y el nivel de T3 $L$ (pmol/L) $(0,71 ; 0,62-0,82, P<0,001)$ según el modelo de regresión de Cox no ajustado, se relacionaron significativamente con todas las causas de mortalidad; mientras que en el análisis multivariante (ajustado), la enfermedad tumoral $(1,60 ; 1,12-2,28, \mathrm{P}=0,009)$, la edad $(1,03 ; 1,01-1,06, \mathrm{P}=0,003)$ y los niveles de T3 $L(0,72 ; 0,63-0,84, P<0,001)$ fueron factores importantes relacionados con todas las causas de mortalidad. Al considerar la mortalidad cardiovascular, sólo la edad (1,05; $1,02-1,07, P<0,001)$ y los niveles de $T 3 \mathrm{~L}(0,71 ; 0,60-0,83, \mathrm{P}<0,001)$ fueron factores importantes en el análisis no ajustado. En el análisis multivariante (ajustado), T3 L $(0,76 ; 0,63-0,91, P=0,004)$ se comportó como el factor más importante asociado a mortalidad cardiovascular, junto con el cáncer $(1,64 ; 1,06-2,55 ; \mathrm{P}=0,027)$ y la edad (años) $(1,05 ; 1,02-1,08, P=0,003)$. 
Tabla 8. Proporciones de riesgo no ajustado y ajustado (con IC del 95\%) para el desarrollo de todas las causas de mortalidad y mortalidad cardiovascular en pacientes clasificados según varias variables (pruebas de función tiroidea) clínicas y analíticas.

\begin{tabular}{|c|c|c|c|c|c|c|c|c|}
\hline \multirow[b]{3}{*}{ Variable } & \multicolumn{4}{|c|}{ Todas las causas de mortalidad } & \multicolumn{4}{|c|}{ Mortalidad cardiovascular } \\
\hline & \multicolumn{2}{|c|}{$\begin{array}{l}\text { Análisis univariante } \\
\text { (sin ajustar) }\end{array}$} & \multicolumn{2}{|c|}{$\begin{array}{c}\text { Análisis multivariante } \\
\text { (ajustado) }\end{array}$} & \multicolumn{2}{|c|}{$\begin{array}{l}\text { Análisis univariante } \\
\text { (sin ajustar) }\end{array}$} & \multicolumn{2}{|c|}{$\begin{array}{c}\text { Análisis multivariante } \\
\text { (ajustado) }\end{array}$} \\
\hline & HR (IC 95\%) & $P$ valor & HR (IC 95\%) & Pvalor & HR (IC 95\%) & P valor & HR (IC 95\%) & Pvalor \\
\hline Sexo (masculino) & $1,05(0,84-1,31)$ & NS & & NS & $1,24(0,94-1,65)$ & NS & & NS \\
\hline Edad (años) & $1,03(1,01-1,05)$ & 0,001 & $1,03(1,01-1,06)$ & 0,003 & $1,05(1,02-1,07)$ & $<0,001$ & $1,05(1,02-1,08)$ & 0,003 \\
\hline Hipertensión & $1,19(0,96-1,50)$ & NS & & NS & $1,06(0,81-1,40)$ & NS & & NS \\
\hline Diabetes mellitus & $1,01(0,78-1,29)$ & NS & & NS & $0,98(0,71-1,36)$ & NS & & NS \\
\hline Dislipemia & $1,14(0,84-1,55)$ & NS & & NS & $1,06(0,71-1,59)$ & NS & & NS \\
\hline $\begin{array}{l}\text { Enfermedad } \\
\text { cardiovascular }\end{array}$ & $0,97(0,76-1,24)$ & NS & & NS & $0,90(0,66-1,23)$ & NS & & NS \\
\hline Cáncer & $0,75(0,54-1,03)$ & NS & $1,60(1,12-2,28)$ & 0,009 & $0,80(0,54-1,17)$ & NS & $1,64(1,06-2,55)$ & 0,027 \\
\hline $\mathrm{TSH}(\mathrm{mU} / \mathrm{L})$ & $1,00(0,97-1,04)$ & NS & & NS & $1,01(0,95-1,07)$ & NS & & NS \\
\hline T4 L (pmol/L) & $0,98(0,95-1,01)$ & NS & & NS & $0,96(0,92-1,00)$ & NS & & NS \\
\hline T3 L (pmol/L) & $0,71(0,62-0,82)$ & $<0,001$ & $0,72(0,63-0,84)$ & $<0,001$ & $0,71(0,60-0,83)$ & $<0,001$ & $0,76(0,63-0,91)$ & 0,004 \\
\hline
\end{tabular}





\section{DISCUSIÓN}

Los principales hallazgos de este estudio muestran una relación significativa entre las pruebas de función tiroidea y la mortalidad en pacientes ancianos hospitalizados por enfermedad aguda, no sólo durante el periodo de hospitalización, sino también a largo plazo tras el alta hospitalaria. Los niveles séricos disminuidos de TSH, T4 L y, en particular, T3 $L$ se asociaron con una mayor mortalidad de todas las causas. Los datos de seguimiento también mostraban que la T3 $L$ baja fue el predictor independiente más importante de todas las causas de mortalidad, tanto durante la hospitalización, como tras el alta hospitalaria. Además, niveles bajos de TSH y de T3 L, también se asociaron con mayor mortalidad cardiovascular en el análisis de supervivencia. Sin embargo, el análisis multivariante mostraba que sólo T3 L y edad, fueron predictores independientes de mortalidad cardiovascular en esta población. Finalmente, no se pudo encontrar ninguna relación significativa entre las pruebas de función tiroidea y la comorbilidad, exceptuando el aumento de los niveles de T4 L en pacientes hipertensos y unos menores niveles de T3 $L$ en los pacientes con diagnóstico de sepsis.

Varios estudios han investigado la prevalencia de disfunción tiroidea, así como su relación con la morbilidad y la mortalidad en la población de edad avanzada $(3,9$, $37,39,40,44,105,107,119,121 ; 124-126)$. Algunos de ellos se han llevado a cabo en la población de ancianos aparentemente $\operatorname{sanos}(3,9,44,105,107,119)$, mientras otros en pacientes hospitalizados $(39,40,121 ; 124-126)$ o en residencias de ancianos (127). Nuestros resultados confirman que la prevalencia de alteraciones en la función 
tiroidea en ancianos hospitalizados por enfermedad aguda es notablemente alta, alrededor de las tres cuartas partes de los pacientes, principalmente a expensas de SEE, como se ha expuesto anteriormente $(39,125,128)$.

La asociación entre alteraciones en la función tiroidea y comorbilidad está establecida en la población general (129). En los ancianos, algún estudio ha encontrado una relación entre hipertiroidismo subclínico y la FA (130), pero no con otras alteraciones cardiovasculares $(46,108)$; sin embargo, otros estudios relacionan tanto el hipertiroidismo subclínico (TSH $<0,1 \mathrm{mU} / \mathrm{L}$ ) como el hipotiroidismo subclínico (TSH $>10 \mathrm{mU} / \mathrm{L}$ ) con un aumento del riesgo de incidencia de ICC en pacientes ancianos con factores de riesgo cardiovascular o enfermedades cardiovasculares previas (129, 131). En el presente estudio se muestra que no hay ninguna relación con la disfunción tiroidea y la prevalencia de ECV con otros factores de riesgo conocidos para la ECV, incluyendo la diabetes mellitus y la dislipemia. Sólo los pacientes hipertensos mostraban un mayor nivel de $\mathrm{T} 4 \mathrm{~L}$, aunque dentro del rango normal, con niveles similares de T3 L y TSH respecto a los pacientes no hipertensos. Esta observación está de acuerdo con un reciente estudio que muestra una correlación positiva entre la masa ventricular izquierda y el nivel de T4 $\mathrm{L}$ en pacientes hipertensos eutiroideos (132). Uno de los últimos estudios publicados relaciona el hipertiroidismo subclínico con el aumento de la mortalidad global y cardiovascular (130). También un reciente estudio australiano, asocia los niveles elevados de T4 L con un aumento de mortalidad por todas las causas en población anciana (116). Sin embargo, el estudio longitudinal del área de CHIANTI, realizado en población anciana que vivía en áreas con deficiencia de yodo, ha relacionado el hipertiroidismo subclínico con una mayor mortalidad por 
cualquier causa a los 6 años, respecto a pacientes eutiroideos, no ocurriendo así para la mortalidad cardiovascular (115). También, en el estudio OCTABAIX (102), no se encuentra asociación entre el hipotiroidismo o hipertiroidismo subclínico con la mortalidad global en ancianos a los 3 años.

El síndrome de T3 baja es la alteración más frecuente en las pruebas de función tiroidea encontrada en ancianos hospitalizados por enfermedad aguda, y se detecta entre un $60-66 \%$ de los pacientes según los estudios $(39,125,128)$. Sin embargo, hay que considerar que en ocasiones esta alteración es transitoria, normalizándose los niveles séricos de T3 L en aproximadamente un 30\% al mes del alta hospitalaria (133). En el presente estudio no se ha encontrado ninguna asociación entre la presencia de síndrome de T3 baja con la comorbilidad prevalente en esta población, lo que sugiere que esta disminución de T3 L podría estar más estrechamente vinculada a la enfermedad aguda que con las enfermedades crónicas de los pacientes.

Por otra parte, al analizar la relación entre las pruebas de función tiroidea con las principales causas de hospitalización, tampoco se encontró ninguna diferencia significativa en los niveles de TSH ni T4 L; en cambio, los niveles de T3 L fueron significativamente más bajos en pacientes ingresados con sepsis respecto a otras causas de hospitalización. Este hallazgo confirma los resultados de estudios anteriores que mostraron una correlación de bajas concentraciones de T3 con la gravedad de la enfermedad en los pacientes hospitalizados ancianos (125). La desnutrición, fármacos, el aumento de citoquinas inflamatorias, -factores que inhiben la 5'-monodeiodinasa-, parecen ser los principales responsables para el desarrollo del síndrome de T3 baja durante la hospitalización por enfermedad aguda (134-136). 
Algunos estudios, pero no todos $(115,116)$ han sugerido que la mayor disminución de TSH y T4 L está asociada con un aumento de mortalidad en los ancianos $(44 ; 105-107 ; 119)$, mientras que un leve hipotiroidismo subclínico parece estar relacionado con un aumento en la supervivencia en esta población $(3,44,107)$. Además, un reciente estudio retrospectivo realizado en pacientes hospitalizados de más de 60 años, mostró que T4 baja y alta TSH se asociaron con un peor pronóstico de morbilidad y de mortalidad durante la hospitalización y después de 18 meses del alta hospitalaria (128).

Este trabajo es uno de los primeros estudios que ha evaluado, prospectivamente, la relación entre las pruebas de función tiroidea en hospitalización por enfermedad aguda y la mortalidad en los pacientes ancianos a largo plazo.

Se encontró que las alteraciones en las pruebas de función tiroidea se asociaban con la mortalidad pero, a diferencia de Mingote y cols. (128), se encontró que los pacientes que murieron tenían los niveles séricos de TSH y T3 L significativamente menores que los pacientes que sobrevivieron, sin diferencias en T4 L. Además, los análisis de supervivencia mostraban un tiempo medio de supervivencia significativamente menor para los tertiles más bajos de T3 L, T4 L y TSH. Sin embargo, un reciente estudio italiano, de características similares al presente trabajo, concluye que el síndrome de la T3 baja, en pacientes ancianos frágiles hospitalizados, se relaciona con el pronóstico a corto plazo pero no a largo plazo; y además el aumento de los niveles de T4 L, en eutiroideos ancianos, es un marcador de peor supervivencia a largo plazo (40). Las diferencias entre el estudio italiano y el presente trabajo, tal vez se puedan explicar con la determinación analítica de las hormonas medidas, los 
criterios de selección de pacientes e interferencias con fármacos que afectan a la función tiroidea.

Existe una asociación bien conocida entre las concentraciones séricas de T3 y la mortalidad en pacientes con enfermedad aguda grave (39; 137-139). De hecho, el bajo nivel de T3 ha sido considerado también como un fuerte marcador predictivo independiente de mortalidad en varios estados patológicos, incluyendo pacientes con enfermedad cardiaca (137), ACVA (104) y hemodiálisis (140).

El presente estudio confirma, no sólo la capacidad del T3 L de predecir la muerte de los pacientes ancianos durante la hospitalización con enfermedad aguda, sino también la relación entre los niveles de T3 L y la mortalidad a largo plazo. Además, encontramos que T3 L fue el predictor más potente de todas las causas de mortalidad y mortalidad cardiovascular, siendo aún más relevante que la edad de los pacientes. La asociación entre los niveles bajos de T3 L y mortalidad cardiovascular ha sido descrita anteriormente en pacientes cardiacos, y se ha considerado como un fuerte predictor de muerte en estos pacientes (137). En nuestro estudio se encontró también, en el análisis de supervivencia, esta asociación entre bajos niveles de T3 L y mortalidad cardiovascular, siendo el más importante predictor en 7 años de mortalidad cardiovascular en pacientes octogenarios, incluso más que la edad.

Respecto a las fortalezas y debilidades de este estudio, el número relativamente grande de pacientes y el tiempo de seguimiento son las principales fortalezas de este estudio. Como se ha comentado anteriormente, el objetivo de este estudio ha sido analizar la relación entre función tiroidea y mortalidad en una gran cohorte de pacientes ancianos ingresados en el Hospital General de Segovia. Dicho 
hospital atiende a toda la población de la provincia y es el único centro de agudos de Segovia, por lo que la muestra recogida en este estudio ha sido claramente representativa de la población anciana con necesidad de ingreso hospitalario de esta provincia. Era esperable que la cohorte de estudio estuviese constituida principalmente por pacientes residentes en la provincia de Segovia, lo cual facilitó en su momento la recogida de datos sobre supervivencia. No obstante, hubo que tener en cuenta el ingreso de un pequeño número de pacientes procedentes de otras provincias, que nos supuso una dificultad para el análisis de la supervivencia y la pérdida de pacientes.

Las dificultades de este estudio fueron las propias de cualquier otro estudio epidemiológico de esta naturaleza, es decir, las inherentes a la recolección ordenada de un gran número de datos de una cohorte numerosa de sujetos. Existieron dificultades en la recogida de datos de historias, ausencia de datos clínicos o analíticos relevantes, ausencia de datos administrativos para la localización posterior del paciente, etc.

Una gran limitación en este estudio fue la imposibilidad de acceder al Registro Civil de Segovia, para averiguar la causa de muerte de muchos de nuestros pacientes que no habían fallecido dentro del Hospital General de Segovia. Esto obligó a continuar la búsqueda, a través de contacto telefónico o las cartas a las familias, cuya información en muchas ocasiones no nos fue de utilidad. También fue escasa la colaboración por parte de los médicos de Atención Primaria, para ayudarnos a recabar las causas de defunción de nuestros pacientes, posiblemente justificada por su falta de 
información. El mayor problema, por tanto, fue la pérdida de sujetos para el análisis de las causas de mortalidad a largo plazo.

En conclusión, los resultados presentados en este trabajo muestran que las alteraciones en las pruebas de función tiroidea están relacionados con la mortalidad en pacientes ancianos hospitalizados por enfermedad aguda, no sólo durante la hospitalización, sino también a largo plazo después del alta hospitalaria. Niveles bajos de T3 $L$ y T4 $L$ y bajas concentraciones séricas de TSH se asocian a una disminución del tiempo de supervivencia, aunque sólo el nivel bajo de T3 L se comporta como un poderoso predictor independiente de todas las causas de mortalidad y mortalidad cardiovascular. 



\section{CONCLUSIONES}

1. La mayoría de los pacientes ancianos hospitalizados por enfermedad aguda presentan alteradas las pruebas de función tiroidea, siendo el SEE la alteración más frecuente, seguido del hipotiroidismo subclínico.

2. Los niveles más bajos de T3 L se detectaron en pacientes sépticos.

3. Los pacientes hipertensos mostraron niveles significativamente mayores de T4 L.

4. Las alteraciones en las pruebas de función tiroidea durante el ingreso se relacionan, tanto con la mortalidad hospitalaria, como con la mortalidad a largo plazo en pacientes ancianos hospitalizados por enfermedad aguda.

5. Los pacientes que fallecieron fueron más mayores en edad y presentaron menores concentraciones séricas de T3 $L$ respecto a los que sobrevivieron, siendo la ECV la principal causa de muerte.

6. La mayor tasa de mortalidad ocurrió tras el alta hospitalaria.

7. Los pacientes fallecidos tenían valores más bajos de tensión arterial sistólica, tensión arterial diastólica, colesterol, TSH y T3 L, así como mayores niveles de glucosa y creatinina que los pacientes que sobrevivieron.

8. Los niveles séricos bajos de T3 L, T4 L y TSH se asocian a una menor supervivencia.

9. Sólo un nivel bajo de T3 L se comportó como un potente predictor independiente de todas las causas de mortalidad y mortalidad cardiovascular. 



\section{REFERENCIAS BIBLIOGRÁFICAS}

1. Díez JJ. Hipotiroidismo en el paciente anciano: importancia clínica y dificultades en el diagnóstico y tratamiento. Med Clín (Barc) 1998; 111(19): 742-750.

2. Mariotti S, Barbesino G, Caturegli P, Bartalena L, Sansoni P, Fagnoni F, et al. Complex alteration of thyroid function in healthy centenarians. J Clin Endocrinol Metab 1993; 77(5): 1130-4.

3. Van den Beld AW, Visser TJ, Feelders RA, Grobbee DE, Lamberts SW. Thyroid hormone concentrations, disease, physical function, and mortality in elderly men. J Clin Endocrinol Metab 2005; 90(12): 6403-9.

4. Atzmon G, Barzilai N, Hollowell JG, Surks MI, Gabriely I. Extreme longevity is associated with increased serum thyrotropin. J Clin Endocrinol Metab 2009; 94(4): 1251-4.

5. Corsonello A, Montesanto A, Berardelli M, De Rango F, Dato S, Mari V, et al. A crosssection analysis of FT3 age-related changes in a group of old and oldest-old subjects, including centenarians' relatives, shows that a down-regulated thyroid function has a familial component and is related to longevity. Age Ageing 2010; 39(6): 723-7.

6. Formiga F, Ferrer A. Thyrotropin serum values and 3-year mortality in nonagenarians. J Gerontol A Biol Sci Med Sci 2010; 65(11): 1250-1.

7. Rozing MP, Houwing-Duistermaat JJ, Slagboom PE, Beekman M, Frölich M, de Craen AJ, et al. Familial longevity is associated with decreased thyroid function. J Clin Endocrinol Metab 2010; 95(11): 4979-84. 
8. Rozing MP, Westendorp RG, de Craen AJ, Frölich M, Heijmans BT, Beekman M, et al. Low serum free triiodothyronine levels mark familial longevity: the Leiden Longevity Study. J Gerontol A Biol Sci Med Sci 2010; 65(4): 365-8.

9. Waring AC, Harrison S, Samuels MH, Ensrud KE, LeBLanc ES, Hoffman AR, et al. Thyroid function and mortality in older men: a prospective study. J Clin Endocrinol Metab 2012; 97(3): 862-70.

10. Fagman $H$, Andersson L, Nilsson $M$. The developing mouse thyroid: embryonic vessel contacts and parenchymal growth pattern during specification, budding, migration, and lobulation. Dev Dyn 2006; 235(2): 444-55.

11. Loevner L.A. Glándulas tiroides y paratiroides: anatomía y patología. En: Som PM, Curtin HD (Eds). Radiología de cabeza y cuello. Editorial Elsevier/Mosby 2004; 2: 2134-57.

12. Hanks J.B. Tiroides. En: Townsend C.M, Beauchand R.D, Evers B.M, Mattox K.L (Eds.). Sabinston. Tratado de cirugía. Fundamentos biológicos de la práctica quirúrgica moderna. Editorial Elsevier Saunders 2005; 1: 947-84.

13. Oré J, Saavedra J. Patología quirúrgica de la glándula tiroides. An Fac Med 2008; 69(3): 182-7.

14. Mariotti S, Franceschi C, Cossarizza A, Pinchera A. The aging thyroid. Endocr Rev 1995; 16(6): 686-715.

15. Sánchez-Franco F. Fisiología tiroidea. Hipertiroidismo. Hipotiroidismo. Tiroiditis. Bocio. En: Casanueva F, Vázquez JA (Eds). Endocrinología clínica. Madrid. Díaz de Santos SA 1995: 73-101. 
16. Brandan Nora C, Llanos Isabel C, Rodríguez Andrea N, Ruiz Díaz D. Hormonas tiroideas. UNNE. Cátedra de Bioquímica 2010; 1(1): 1-15.

17. Guyton AC. Hormonas tiroideas metabólicas. En: Guyton AC (Ed) Tratado de fisiología médica. Editorial Interamericana- McGraw-Hill 1995: 867-78.

18. Haedo A. Disfunción tiroidea como factor de riesgo de fibrilación auricular. Rev Electro y Arritmias 2012; 6: 9-12.

19. Méndez Gómez N, Silva Hernández D, Morejón Téllez LF, Rodríguez Díaz A. Manifestaciones psiquiátricas en enfermedades endocrinas. Rev Cub Med Mil 1996; 25(1): 525-30.

20. Rubin DI. Neurologic manifestations of hyperthyroidism and Graves' disease. En: UpToDate (Basow DS, ed). Waltham, MA; UpToDate 2009; 302(11): 1171-78.

21. Maggio M, Colizzi E, Fisichella A, Valenti G, Ceresini G, Dall'aglio E, et al. Stress hormones, sleep deprivation and cognition in older adults. Maturitas 2013; 76(1): 22-44.

22. Volpé R. Graves' Disease. In: Thyroid, function \& disease. J Clin Endocrinol Metab 1989; 68(1): 107-13.

23. Canaris GJ, Manowitz NR, Mayor GM, Ridgway EC. The Colorado thyroid disease prevalence study. Arch Intern Med 2000; 160(4): 526-34.

24. Hollowell JG, Staehling NW, Flanders WD, Hannon WH, Gunter EW, Spencer CA, Braverman LE. Serum TSH, T(4), and thyroid antibodies in the United States population (1988 to 1994): National Health and Nutrition Examination Survey (NHANES III). J Clin Endocrinol Metab 2002; 87(2): 489-99. 
25. Brochmann H, Bjoro T, Gaarder PI, Hanson F, Frey HM. Prevalence of thyroid dysfunction in elderly subjects: a randomized study in a Norwegian rural community (Naeroy). Acta Endocrinol (Copenh) 1988; 117(1): 7-12.

26. Vanderpump MP, Tunbridge WM, French JM, Appleton D, Bates D, Clark F, et al. The incidence of thyroid disorders in the community: A twenty-year follow-up of the Whickham Survey. Clin Endocrinol (Oxf) 1995; 43(1): 55-68.

27. Aghini-Lombardi F, Antonangeli L, Martino E, Vitti P, Maccherini $D$, Leoli $F$, et al. The spectrum of thyroid disorders in an iodine-deficient community: The Pescopagano survey. J Clin Endocrinol Metab 1999; 84(2): 561-6.

28. Meyers B, Gionet M, Abreau C, Robuschi G, Pino S, Braverman L, et al. Lodine intake probably affects the incidence of hypothyroidism and Hashimoto thyroiditis in elderly women. J Nucl Med 1986; 27(6): 909(A).

29. Luboshitzky R, Oberman AS, Kaufman N, Reichman N, Flatau E. Prevalence of cognitive dysfunction and hypothyroidism in al elderly community population. Isr J Med Sci 1996; 32(1): 60-5.

30. Tunbridge WM, Evered DC, Hall R, Appelton D, Brewis M, Clark F, et al. The spectrum of thyroid disease in a community: the Wickham survey. Clin Endocrinol (Oxf) 1977; 7(6): 481-93.

31. Campbell AJ, Reinken J, Allan BC. Thyroid disease in the elderly in the community. Age Ageing 1981; 10(1): 47-52.

32. Bagchi N, Brown TR, Parish RF. Thyroid dysfunction in adults over age 55 years. A study in an urban US community. Arch Intern Med 1990; 150(4): 785-7. 
33. Parle JV, Franklyn JA, Cross KW, Jones SC, Sheppard MC. Prevalence and follow-up of abnormal thyrotrophin (TSH) concentrations in the elderly in the United Kingdom. Clin Endocrinol (Oxf) 1991; 34(1): 77-83.

34. Seck T, Scheidt-Nave C, Ziegler R, Pfeilschifter J. Prevalence of thyroid gland dysfunctions in 50 to 80 year-old patients. An epidemiologic cross-sectional study in a southwestern community. Med Klin (Munich) 1997; 92(11): 642-6.

35. Chuang CC, Wang ST, Wang PW, Yu ML. Prevalence of thyroid dysfunction in the elderly of Taiwan. Gerontology 1998; 44(3): 162-7.

36. Knudsen N, Bulow I, Jorgensen T, Laurberg P, Ovensen L, Perrild H. Comparative study of thyroid function and types of thyroid dysfunction in two areas in Denmark with slightly different iodine status. Eur J Endocrinol 2000; 143(4): 48591.

37. Díez JJ, Molina I, Ibars MT. Prevalence of thyroid dysfunction in adults over age 60 years from an urban community. Exp Clin Endocrinol Diabetes 2003; 111(8): 4805.

38. Ibars MT, Díez JJ. Prevalence of thyroid dysfunction among the elderly. Aten Primaria 2005; 15;35(6): 329-30.

39. Iglesias P, Muñoz A, Prado F, Guerrero MT, Macías MC, Ridruejo E, et al. Alterations in thyroid function tests in aged hospitalized patients: prevalence, aetiology and clinical outcome. Clin Endocrinol (Oxf) 2009; 70(6): 961-7.

40. De Alfieri W, Nisticò F, Borgogni T, Riello F, Cellai F, Mori C, et al. Thyroid hormones as predictors of short - and long-term mortality in very old hospitalized patients. J Gerontol A Biol Sci Med Sci 2013; 68(9): 1122-8. 
41. Díez JJ. Hyperthyroidism in patients older than 55 years: an analysis of the etiology and management. Gerontology 2003; 49(5): 316-23.

42. Díez JJ, Iglesias P. Mortality in elderly patients with subclinical hyperthyroidism. Lancet 2002; 359(9308): 797.

43. Díez JJ. Hypothyroidism in patients older than 55 years: an analysis of the etiology and assessment of the effectiveness of therapy. J Gerontol A Biol Sci Med Sci 2002; 57(5): M315-20.

44. Gussekloo J, van Exel E, de Craen AJ, Meinders AE, Frölich M, Westendorp RG. Thyroid status, disability and cognitive function, and survival in old age. JAMA 2004; 292(21): 2591-9.

45. Mahoney FI, Barthel DW. Functional evaluation: the Barthel index. Md State Med J $1965 ; 14: 61-5$.

46. Sawin CT, Geller A, Wolf PA, Belanger AJ, Baker E, Bacharach P, et al. Low serum thyrotropin concentrations as risk factor for atrial fibrillation in older persons. $\mathrm{N}$ Engl J Med 1994; 331(19): 1249-52.

47. Roberts CG, Ladenson PW. Hypothyroidism. Lancet 2004; 363(9411): 793-803.

48. Duntas LH. Thyroid disease and lipids. Thyroid 2002; 12(4): 287-93.

49. Wang WY, Tang YD, Yang M, Cui C, Mu M, Qian J, Yang YJ. Free triiodothyronine level indicates the degree of myocardial injury in patients with acute ST-elevation myocardial infarction. Chin Med J (Engl) 2013; 126(20): 3926-9.

50. Pfister R, Strack N, Wielckens K, Malchau G, Erdmann E, Schneider CA. The relationship and prognostic impact of low-T3 syndrome and NT-pro-BNP in cardiovascular patients. Int J Cardiol 2010; 144(2): 187-90. 
51. Coceani M, lervasi G, Pingitore A, Carpeggiani C, L'Abbate A. Thyroid hormone and coronary artery disease: from clinical correlations to prognostic implications. Clin Cardiol 2009; 32(7): 380-5.

52. Das KC, Mukherjee M, Sarkar TK, Rastogi-GK. Erythropoiesis and erythropoietin in hypo - and hyperthyroidim. J Clin Endocrinol Metab 1975; 40 (2): 211-20.

53. Kasuga K, Naruse S, Umeda M, Tanaka M, Fujita N. Case of cerebral venous thrombosis due to graves'disease with increased factor VIII activity. Rinsho Shinkeigaku 200646 (4): 273-3.

54. Chen YH, Lin HJ, Chen KT. Rare presentations of hyperthyroidism--Basedow's paraplegia and pancytopenia. Am J Emerg Med 2009; 27(2): 258.e1-2.

55. Horton L, Coburn RJ, England JM, Himsworth RL. The haematology of hypothyroidism. Q J Med 1976; 45 (177): 101-23.

56. Cines DB, Liebman HA. The Immune Thrombocytopenia Syndrome: A Disorder of Diverse Pathogenesis and Clinical Presentation. Hematol Oncol Clin North Am 2009; 23(6): 1155-61.

57. Marvisi M, Zambrelli P, Brianti M, Civardi G, Lampugnani R, Delsignore R. Pulmonary hypertension is frequent in hyperthyroidism and normalizes after therapy. Eur J Intern Med 2006; 17(4): 267-71.

58. Nakchbandi IA, Wirth JA, Inzucchi SE. Pulmonary hypertension caused by Graves' thyrotoxicosis: normal pulmonary hemodynamics restored by (131) I treatment. Chest 1999; 116(5): 1483-5.

59. Zwillich CW, Pierson DJ, Hofeldt FD, Lufkin EG, Weil JV. Ventilatory control in myxedema and hypothyroidsm. N Engl J Med 1975; 292(13): 662-5. 
60. Martínez FJ, Bermúdez-Gómez M, Celli BR. Hypothyroidism. A reversible cause of diaphragmatic dysfunction. Chest 1989; 96(5): 1059-63.

61. Astrom KE, Kugelberg E, Muller R. Hypothyroid miopathy. Arch Neurol 1961; 5: 472-82.

62. Lin CC, Tsan KW, Chen PJ. The relationship between sleep apnea syndrome and hypothyroidism. Chest 1992; 102(6): 1663-7.

63. Misiolek M, Marek B, Namyslowski G, Scierski W, Zwirska-Korczala K, KazmierczakZagorska Z, et al. Sleep apnea syndrome and snoring in patients with hypothyroidism with relation to overweight. J Physiol Pharmacol 2007; 58(1): 7785.

64. Resta O, Carratù P, Carpagnano GE, Maniscalco M, Di Gioia G, Lacedonia D, et al. Influence of subclinical hypothyroidism and T4 treatment on the prevalence and severity of obstructive sleep apnoea syndrome (OSAS). J Endocrinol Invest 2005; 28(10): 893-8.

65. Seyhan EC, Cetinkaya E, Altin S, Gencoğlu A, Simsek N. The incidence of sick euthyroid syndrome in non-small cell lung cancer patients. Tuberk Toraks 2008; 56(2): 163-70.

66. Kung AW. Neuromuscular complications of thyrotoxicosis. Clin Endocrinol (Oxf) 2007; 67(5): 645-50.

67. George G. Hypothyroidism presenting as puzzling myalgias and cramps in 3 patients. J Clin Rheumatol 2007; 13(5): 273-5.

68. Montoro C, Cruz JA, Agudo P, Gilsanz C. Miopatía hipotiroidea. An Med Interna (Madrid) 2000; 17: 309-310. 
69. Chonchol M, Lippi G, Salvagno G, Zoppini G, Muggeo M, Targher G. Prevalence of subclinical hypothyroidism in patients with chronic kidney disease. Clin J Am Soc Nephrol 2008; 3(5): 1296-300.

70. Katz Al, Emmanouel DS, Lindheimer MD. Thyroid hormone and the Kidney. Nephron 1975; 15(3-5): 223-49.

71. Montenegro J, González O, Saracho R, Aguirre R, González O, Martínez I. Changes in renal function in primary hypothyroidism. Am J Kidney Dis 1996; 27(2): 195-8.

72. Heras M, Fernández Reyes MJ, Sánchez R, Álvarez-Ude F. Changes in renal function caused by primary autoimmune hypothyroidism reversible with levothyroxine. Nefrología 2006; 26(4): 508-9.

73. Feinstein El, Kaptein EM, Nicoloff JT, Massry SG. Thyroid function in patients with nephrotic syndrome and normal renal function. Am J Nephrol 1982; 2(2): 70-6.

74. Iglesias P, Olea T, Vega-Cabrera C, Heras M, Bajo MA, del Peso G, et al. Thyroid function tests in acute kidney injury. J Nephrol 2013; 26(1): 164-72.

75. Zoccali C, Mallamaci F, Tripepi G, Cutrupi S, Pizzini P. Low triiodothyronine and survival in end-stage renal disease. Kidney Int 2006; 70(3): 523-8.

76. Enia G, Panuccio V, Cutrupi S, Pizzini P, Tripepi G, Mallamaci F, Zoccali C. Subclinical hypothyroidism is linked to micro-inflammation and predicts death in continuous ambulatory peritoneal dialysis. Nephrol Dial Transplant 2007; 22(2): 538-44.

77. Meuwese CL, Carrero JJ, Cabezas-Rodríguez I, Heimburger O, Barany P, Lindholm B, et al. Nonthyroidal illness: a risk factor for coronary calcification and arterial stiffness in patients undergoing peritoneal dialysis?. J Intern Med 2013; 274(6): 584-93. 
78. Yang JW, Han ST, Song SH, Kim MK, Kim JS, Choi SO, Han BG. Serum T3 level can predict cardiovascular events and all-cause mortality rates in CKD patients with proteinuria. Ren Fail 2012; 34(3): 364-72.

79. Malik $\mathrm{R}$, Hodgson $\mathrm{H}$. The relationship between the thyroid gland and the liver. QJM 2002; 95(9): 559-69.

80. Kubota S, Takata K, Arishima T, Ohye H, Nishihara E, Kudo T, et al. The prevalence of transient thyrotoxicosis after antithyroid drug therapy in patients with Graves' disease. Thyroid 2008; 18(1): 63-6.

81. Hull K, Horenstein R, Naglieri R, Munir K, Ghany M, Celi FS. Two cases of thyroid storm associated cholestatic jaundice. Endocr Pract 2007; 13(5): 476-80.

82. Macías G, Castello T, Aymond A, Schroder T, Fainboim H, Reyes A, et al. Ictericia colestásica e hipertiroidismo. Gastroenterol Hepatol 1996; 23: 1030-34.

83. Chiu WY, Yang CC, Huang IC, Huang TS. Dysphagia as a manifestation of thyrotoxicosis: report of three cases and literatura review. Dysphagia 2004; 19(2): 120-4.

84. Branski D, Levy J, Globus M., Aviad I, Keren A, Chowers I. Dysphagia as a primary manifestation of hyperthyroidism. J Clin Gastroenterol 1984; 6(5): 437-40.

85. Meshkinpour H, Afrasiabi MA, Valenta L. Esophageal motor function in Graves' disease. Dig Dis Sci 1979; 24(2): 159-61.

86. Ebert EC. The thyroid and the gut. J Clin Gastroenterol 2010; 44(6): 402-6.

87. Loria $\mathrm{P}$, Carulli L, Bertolotti $\mathrm{M}$, Lonardo A. Endocrine and liver interaction: the role of endocrine pathways in NASH. Nat Rev Gastroenterol Hepatol 2009; 6(4): 23647. 
88. Targher G, Montagnana M, Salvagno G, Moghetti P, Zoppini G, Muggeo M, Lippi G. Association between serum TSH, free T4 and serum liver enzyme activities in a large cohort of unselected outpatients. Clin Endocrinol (Oxf) 2008; 68(3): 481-4.

89. Schussler GC, Schaffner F, Korn F. Increased serum thyroid hormone binding and decreased free hormone in chronic active liver disease. N Engl J Med 1978; 299(10): 510-5.

90. Ji JS, Chae HS, Cho YS, Kim HK, Kim SS, Kim CW, et al. Myxedema ascites: case report and literature review. J Korean Med Sci 2006; 21(4): 761-4.

91. Pustorino S, Foti M, Calipari G, Pustorino E, Ferraro R, Guerrisi O, Germanotta G. Thyroid intestinal motility interactions summary. Minerva Gastroenterol Dietol 2004; 50(4): 305-15.

92. Kaise $M$, Sumitomo $H$, Hashimoto $K$, Takahashi $Y$, Matsui J, Tanaka S, et al. Hypergastrinemia and type A gastritis in Basedow's disease. Nihon Shokakibyo Gakkai Zasshi 1992; 89(9): 1990-5.

93. Lauritano EC, Bilotta AL, Gabrielli M, Scarpellini E, Lupascu A, Laginestra A, et al. Association between hypothyroidism and small intestinal bacterial overgrowth. J Clin Endocrinol Metab 2007; 92(11): 4180-4.

94. Lee JS, Buzková P, Fink HA, Vu J, Carbone L, Chen Z, et al. Subclinical thyroid dysfunction and incident hip fracture in older adults. Arch Intern Med 2010; 170(21): 1876-83.

95. Ling XW, Howe TS, Koh JS, Wong MK, Nq AC. Preoperative thyroid dysfunction predicts 30-day postoperative complications in elderly patients with hip fracture. Geriatr Orthop Surg Rehabil 2013; 4(2): 43-9. 
96. Ko YJ, Kim JY, Lee J, Song HJ, Kim JY, Choi NK, Park BJ. Levothyroxine dose and fracture risk according to the osteoporosis status in elderly women. J Prev Med Public Health 2014; 47(1): 36-46.

97. Flynn RW, Bonellie SR, Junt RT, MacDonald TM, Morris AD, Leese GP. Serum thyroid-stimulating hormone concentration and morbidity from cardiovascular disease and fractures in patients on long-term thyroxine therapy. J Clin Endocrinol Metab 2010; 95(1): 186-93.

98. Bhandarkar SD, Satoskar RS. Clinical manifestations of thyrotoxicosis. Indian J Med Sci 1963; 17: 650-6.

99. Bunevicius R, Prange AJ Jr. Psychiatric manifestations of Graves' hyperthyroidism: pathophysiology and treatment options. CNS Drugs 2006; 20 (11): 897-909.

100. Rozendaal FP. Hyperthyroidism in the elderly: aspecific signs may cause a delay in diagnosis. Tijdschr Gerontol Geriatr 2005; 36(2): 77-80.

101. Resta F, Triggiani V, Barile G, Benigno M, Suppressa P, Giagulli VA, et al. Subclinical hypothyroidism and cognitive dysfunction in the elderly. Endocr Metab Immune Disord Drug Targets 2012; 12(3): 260-7.

102. Formiga F, Ferrer A, Padros G, Contra A, Corbella X, Pujol R; Octabaix Study Group. Thyroid status and functional and cognitive status at baseline and survival after 3 years of follow-up: the OCTABAIX study. Eur J Endocrinol 2013; 170(1): 69-75.

103. Mafrica F, Fodale V. Thyroid function, Alzheimer's disease and postoperative cognitive dysfunction: a tale of dangerous liaisons?. J Alzheimers Dis 2008; 14(1): 95-105. 
104. Alevizaki M, Synetou M, Xynos K, Pappa T, Vemmos KN. Low triiodothyronine: a strong predictor of outcome in acute stroke patients. Eur J Clin Invest 2007; 37(8): 651-7.

105. Parle JV, Maisonneuve P, Sheppard MC, Boyle P, Franklyn JA. Prediction of allcause and cardiovascular mortality in elderly people from one low serum thyrotropin results: a 10-year cohort study. Lancet 2001; 358(9285): 861-5.

106. Singer RB. Mortality in a complete 4-year follow up of 85-year-old residents of Leiden, classified by serum level of thyrotropin and thyroxine. J Insur Med 2006; 38(1): 14-9.

107. Gussekloo J, van Exel E, de Craen AJ, Meinders AE, Frölich M, Westendorp RG. Thyroid function, activities of daily living and survival in extreme old age: the 'Leiden 85-plus Study'. Ned Tijdschr Geneeskd 2006; 150(2): 90-6.

108. Cappola AR, Fried LP, Arnold AM, Danese MD, Kuller LH, Burke GL, et al. Thyroid status, cardiovascular risk, and mortality in older adults. JAMA 2006; 295(9): 1033-41.

109. Rehman SU, Cope DW, Senseney AD, Brzezinski W. Thyroid disorders in elderly patients. South Med J 2005; 98(5): 543-9.

110. Faggiano A, Del Prete M, Marciello F, Marotta V, Ramundo V, Colao A. Thyroid diseases in elderly. Minerva Endocrinol 2011; 36(3): 211-31.

111. Feldkamp J. Subclinical hyperthyroidism. Dtsch Med Wochenschr 2013; 138(42): 2146-50.

112. Wilkes S, Pearce S, Ryan V, Rapley T, Ingoe L, Razvi S. Study of Optimal Replacement of Thyroxine in the EIDerly (SORTED): protocol for a mixed methods 
feasibility study to assess the clinical utility of lower dose thyroxine in elderly hypothyroid patients: study protocol for a randomized controlled trial. Trials 2013; 14: 83.

113. Franklyn JA, Maisonneuve P, Sheppard MC, Betteridge J, Boyle P. Mortality after the treatment of hyperthyroidism with radioactive iodine. N Engl J Med 1998; 338(11): 712-8.

114. Franklyn JA, Sheppard MC, Maisonneuve P. Thyroid function and mortality in patients treated for hyperthyroidism. JAMA 2005; 294(1): 71-80.

115. Ceresini G, Ceda GP, Lauretani F, Maggio M, Usberti E, Marina M, et al. Thyroid status and 6-year mortality in elderly people living in a mildly iodine-deficient area: the aging in the Chianti Area Study. J Am Geriatr Soc 2013; 61(6): 868-74.

116. Yeap BB, Alfonso H, Hankey GJ, Flicker L, Golledge J, Norman PE, Chubb SA. Higher free thyroxine levels are associated with all-cause mortality in euthyroid older men: the Health In Men Study. Eur J Endocrinol 2013; 169(4): 401-8.

117. Imaizumi M, Akahoshi M, Ichimaru S, Nakashima E, Hida A, Soda M, et al. Risk for ischemic heart disease and all-cause mortality in subclinical hypothyroidism. J Clin Endocrinol Metab 2004; 89(7): 3365-70.

118. Rodondi N, Newman AB, Vittinghoff E, de Rekeneire N, Satterfield S, Harris TB, Bauer DC. Subclinical hypothyroidism and the risk of heart failure, other cardiovascular events, and death. Arch Intern Med 2005; 165(21): 2460-6.

119. Waring AC, Arnold AM, Newman AB, Bùzková $P$, Hirsch C, Cappola AR. Longitudinal changes in thyroid function in the oldest old and survival: the 
cardiovascular health study all-stars study. J Clin Endocrinol Metab 2012; 97(11): 3944-50.

120. Speakman JR, Selman C, McLaren JS, Harper EJ. Living fast, dying when? The link between aging and energetics. J Nutr 2002; 132(6 Suppl 2): 1583S-97S.

121. Bossoni S, Cossi S, Marengoni A, De Martinis M, Calabrese P, Leonardi R, et al. Low T3 syndrome and outcome in elderly hospitalized geriatric patients. J Endocrinol Invest 2002; 25(10 Suppl): 73-74.

122. Fenzi G, Marcocci C, Aghini-Lombardi F, Pinchera A. Clinical approach to goitre. Baillieres Clin Endocrinol Metab 1988; 2(3): 671-682.

123. Shah S, Vanclay F, Cooper B. Improving the sensitivity of the Barthel Index for stroke rehabilitation. J Clin Epidemiol 1989; 42(8): 703-9.

124. Atkinson RL, Dahms WT, Fisher DA, Nichols AL. Occult thyroid disease in an elderly hospitalized population. J Gerontol 1978; 33(3): 372-6.

125. Simons RJ, Simon JM, Demers LM, Santen RJ. Thyroid dysfunction in elderly hospitalized patients. Effect of age and severity of illness. Arch Intern Med 1990; 150(6): 1249-53.

126. Bossoni S, Cossi S, Marengoni A, De Martinis M, Calabrese $P$, Leonardi R, et al. The negative role of subclinical thyrotoxicosis on the outcome of hospitalized geriatric patients. J Endocrinol Invest 2002; 25(10 Suppl): 64-65.

127. Cobler JL, Williams ME, Greenland P. Thyrotoxicosis in institutionalized elderly patients with atrial fibrillation. Arch Intern Med 1984; 144(9): 1758-60. 
128. Mingote $E$, Meroño T, Rujelman R, Marquez A, Fossati $P$, Gurfinkiel $M$, et al. High TSH and low T4 as prognostic markers in older patients. Hormones (Athens) 2012; 11(3): 350-5.

129. Gencer B, Collet TH, Virgini V, Bauer DC, Gussekloo J, Cappola AR, et al. Subclinical thyroid dysfunction and the risk of heart failure events: an individual participant data analysis from 6 prospective cohorts. Circulation 2012; 126(9): 1040-9.

130. Palazzo MG, Suter PM. Delivery dependent oxygen consumption in patients with septic shock: daily variations, relationship with outcome and the sick-euthyroid syndrome. Intensive Care Med 1991; 17(6): 325-32.

131. Nanchen D, Gussekloo J, Westendorp RG, Stott DJ, Jukema JW, Trompet S, et al. Subclinical thyroid dysfunction and the risk of heart failure in older persons at high cardiovascular risk. J Clin Endocrinol Metab 2012; 97(3): 852-61.

132. Lida $M$, Yamamoto $M$, Ishiguro $Y$, Yamazaki $M$, Honjo $H$, Kamiya K. Thyroid hormone within the normal range is associated with left ventricular mass in patients with hypertension. J Am Soc Hypertens 2012; 6(4): 261-9.

133. Iglesias P, Muñoz A, Prado F, Guerrero MT, Macías MC, Ridruejo E, et al. Serum thyrotropin concentration is an early marker of normalization of low triiodothyronine syndrome in aged hospitalized patients after discharge. J Endocrinol Invest 2010; 33(9): 607-11.

134. Van der Poll T, Romijn JA, Wiersinga WM, Sauerwein HP. Tumor necrosis factor: a putative mediator of the sick euthyroid syndrome in man. J Clin Endocrinol Metab 1990; 71(6): 1567-72. 
135. Stouthard JM, Van der Poll T, Endert E, Bakker PJ, Veenhof CH, Sauerwein HP, Romijn JA. Effects of acute and chronic interleukin-6 administration on thyroid hormone metabolism in humans. J Clin Endocrinol Metab 1994; 79(5): 1342-6.

136. Adler SM, Wartofsky L. The nonthyroidal illness syndrome. Endocrinol Metab Clin North Am 2007; 36(3): 657-72, vi.

137. Lervasi G, Pingitore A, Landi P, Raciti M, Ripoli A, Scarlattini M, et al. Low-T3 syndrome: a strong prognostic predictor of death in patients with heart disease. Circulation 2003; 107(5): 708-13.

138. Peeters RP, Wouters PJ, Van Toor H, Kaptein E, Visser TJ, Van den Berghe G. Serum 3,3',5'-triiodothyronine(rT3) and 3,5,3'-triiodothyronine/rT3 are prognostic markers in critically ill patients and are associated with postmortem tissue deiodinase activities. J Clin Endocrinol Metab 2005; 90(8): 4559-65.

139. Plikat K, Langgartner J, Buettner R, Bollheimer LC, Woenckhaus U, Schölmerich J, Wrede CE. Frequency and outcome of patients with nonthyroidal illness syndrome in a medical intensive care unit. Metabolism 2007; 56(2): 239-44.

140. Zoccali C, Mallamaci F. Thyroid function and clinical outcomes in kidney failure. Clin J Am Soc Nephrol 2012; 7(1): 12-4. 



\section{ABREVIATURAS}

ACVA: Accidente cerebrovascular agudo.

Anti-TG: Anti-tiroglobulina.

Anti-TPO: Anti-peroxidasa tiroidea.

Cl: Cardiopatía isquémica.

cm: centímetro.

DS: Desviación estándar.

EAP: Enfermedad arterial periférica.

ECV: Enfermedad cardiovascular.

EPO: Eritropoyetina.

ERC: Enfermedad renal crónica.

FA: Fibrilación auricular.

FEVI: Fracción de eyección del ventrículo izquierdo.

FG: Filtrado glomerular.

FRA: Fracaso renal agudo.

HDA: Hemorragia digestiva aguda.

HHT: Hipotálamo-hipófisis-tiroideo.

HR: Razones de riesgo (hazard ratios).

HTP: Hipertensión pulmonar.

IAM: Infarto agudo de miocardio.

IC: Intervalo de confianza.

ICC: Insuficiencia cardiaca congestiva.

IMC: Índice de masa corporal.

MMSE: Mini Mental State Examination. 
mU/L: Miliunidades internacionales por litro.

NT-pro-BNP: Fracción aminoterminal del péptido natriurético cerebral o péptido natriurético tipo $\mathrm{B}$.

pmol/L: Picomol por litro.

PTH: Parathormona.

PTI: Púrpura trombocitopénica idiopática.

SAOS: Síndrome de apnea obstructiva del sueño.

SCACEST: Síndrome coronario agudo con elevación del ST.

SEE: Síndrome del eutiroideo enfermo.

SMR: Razones de mortalidad estandarizadas.

SNC: Sistema nervioso central.

T3 L: T3 libre.

T3: Triyodotironina.

T4 L: T4 libre.

T4: Tetrayodotirosina.

TBG: Globulina fijadora de tiroxina.

TRH: Hormona liberadora de tirotropina.

TSH: Hormona estimulante del tiroides.

VIH: Virus de la inmunodeficiencia humana. 



\section{INDICE DE TABLAS Y FIGURAS}

\subsection{Tablas}

- Tabla 1: Cambios en la función tiroidea asociados al envejecimiento.

- Tabla 2. Prevalencia de disfunción tiroidea según la edad y género.

- Tabla 3. Datos clínicos, analíticos y comorbilidades más frecuentes de los pacientes del estudio.

- Tabla 4. Causas de mortalidad (enfermedades circulatorias y otras enfermedades no circulatorias).

- Tabla 5. Distribución de los pacientes de acuerdo a los valores de referencia de los parámetros de la glándula tiroidea en relación con su estado vital.

- Tabla 6. Datos clínicos y analíticos de los pacientes del estudio a la entrada en función de su estado vital al final del estudio.

- Tabla 7. Supervivencia en meses (mediana) según tertiles de TSH, T4 L y T3 L para todos los casos.

- Tabla 8. Proporciones de riesgo no ajustado y ajustado (con IC del 95\%) para el desarrollo de todas las causas de mortalidad y mortalidad cardiovascular en pacientes clasificados según varias variables (pruebas de función tiroidea) clínicas y analíticas. 


\subsection{Figuras}

- Figura 1. Prevalencia del hipotiroidismo e hipertiroidismo (franco y subclínico) en la población general.

- Figura 2. Prevalencia de disfunción tiroidea en mayores de 60 años en la Comunidad de Madrid.

- Figura 3. Distribución de los pacientes según el sexo.

- Figura 4. Resultados de la función tiroidea en nuestros pacientes.

- Figura 5. Niveles de T4 L en pacientes hipertensos frente a no hipertensos.

- Figura 6. Principales causas de ingreso hospitalario.

- Figura 7. Niveles de T3 L en determinadas causas de ingreso.

- Figura 8. Estado vital de los pacientes el 1 de enero de 2012.

- Figura 9. Alto valor predictivo de supervivencia de T3 L.

- Figura 10. Concentraciones séricas de TSH y T3 $L$ en los pacientes que fallecieron durante el ingreso y en aquellos que lo hicieron tras el alta hospitalaria.

- Figura 11. Causas de mortalidad más relevantes en la población estudiada.

- Figura 12. Análisis de supervivencia de Kaplan-Meier para todas las causas de mortalidad y mortalidad cardiovascular, en los pacientes ancianos ingresados por enfermedad aguda, estratificado según tertiles de TSH, T4 L y T3 L. 



\section{ANEXOS}

\subsection{Mini Mental State Examination}

\section{MINI MENTAL STATE EXAMINATION}

\section{ORIENTACIÓN}

- ¿En qué año estamos? 0-1

- ¿En qué estación? 0-1

- ¿En qué día (fecha)? 0-1

- ¿En qué mes? 0-1

- ¿En qué día de la semana? 0-1

- ¿En qué hospital (o lugar) estamos? 0-1

- ¿En qué piso (o planta, sala, servicio)? 0-1

- ¿En qué pueblo (ciudad)? 0-1

- ¿En qué provincia estamos? 0-1

- ¿En qué país (o nación, autonomía)? 0-1

\section{FIJACIÓN}

-Nombre tres palabras "Peseta-Caballo-Manzana" (o Balón-Bandera-Árbol) a razón de una por segundo. Luego se pide al paciente que las repita. Esta primera repetición otorga la puntuación. Otorgue un punto por cada palabra correcta, pero continúe diciéndolas hasta que el sujeto repita las tres, hasta un máximo de seis veces.

\section{CONCENTRACIÓN Y CÁLCULO}

-Si tiene 30 pesetas y me va dando de tres en tres, ¿cuántas le van quedando?. Detenga la prueba tras cinco sustracciones. Si el sujeto no puede realizar esta prueba, pídale que deletree la palabra "MUNDO" al revés.

30 0-1 27 0-1 24 0-1 21 0-1 18 0-1 (O 0-1 D 0-1 N 0-1 U 0-1 M0-1). 


\section{MEMORIA}

-Preguntar por las tres palabras mencionadas anteriormente.

Peseta 0-1, Caballo 0-1, Manzana 0-1, (Balón 0-1 Bandera 0-1 Árbol 0-1).

LENGUAJE Y CONSTRUCCIÓN

-Mostrarle un lápiz o un bolígrafo y preguntar ¿qué es esto?. Hacer lo mismo con un reloj de pulsera. Lápiz 0-1, Reloj 0-1.

-Pedirle que repita la frase: "Ni sí, ni no, ni pero" (o "En un trigal había cinco perros")

$0-1$

-Pedirle que siga la orden: "Coja un papel con la mano derecha, dóblelo por la mitad, y póngalo en el suelo".

Coge con mano derecha 0-1, dobla por mitad 0-1, pone en suelo 0-1.

-Escriba legiblemente en un papel "Cierre los ojos". Pídale que lo lea y haga lo que dice la frase $0-1$.

-Que escriba una frase (con sujeto y predicado) 0-1.

-Dibuje dos pentágonos intersectados y pida al sujeto que los copie tal cual. Para otorgar un punto deben estar presentes los diez ángulos y la intersección 0-1.

PUNTUACIONES DE REFERENCIA

27 ó más: normal.

24 ó menos: sospecha patológica.

12-24: deterioro.

9-12: demencia.

Puntuación Total (Máx.: 30 puntos) 
10.2. Índice de Barthel

\begin{tabular}{|c|c|}
\hline & ÍNDICE DE BARTHEL \\
\hline Comida & \\
\hline & $\begin{array}{l}10 \text { Independiente. Capaz de comer por sí solo en un tiempo } \\
\text { razonable. La comida puede ser cocinada y servida por } \\
\text { otra persona. }\end{array}$ \\
\hline & $\begin{array}{l}5 \text { Necesita ayuda para cortar la carne, extender la } \\
\text { mantequilla pero es capaz de comer solo. }\end{array}$ \\
\hline & Dependiente. Necesita ser alimentado por otra persona. \\
\hline Lavado (baño) & \\
\hline & $\begin{array}{l}5 \text { Independiente. Capaz de lavarse entero, de entrar y salir } \\
\text { del baño sin ayuda y de hacerlo sin que una persona } \\
\text { supervise. }\end{array}$ \\
\hline & Dependiente. Necesita algún tipo de ayuda o supervisión. \\
\hline Vestido & \\
\hline & $\begin{array}{l}10 \text { Independiente. Capaz de ponerse y quitarse la ropa sin } \\
\text { ayuda. }\end{array}$ \\
\hline & $\begin{array}{l}5 \text { Necesita ayuda. Realiza sin ayuda más de la mitad de estas } \\
\text { tareas en un tiempo razonable. }\end{array}$ \\
\hline & Dependiente. Necesita ayuda para las mismas. \\
\hline Arreglo & \\
\hline & $\begin{array}{l}5 \text { Independiente. Realiza todas las actividades personales } \\
\text { sin ayuda alguna. Los complementos necesarios pueden } \\
\text { ser provistos por alguna persona. }\end{array}$ \\
\hline & 0 Dependiente. Necesita alguna ayuda. \\
\hline Deposición & \\
\hline & 10 Continente. No presenta episodios de incontinencia. \\
\hline & $\begin{array}{l}5 \text { Accidente ocasional. Menos de una vez por semana o } \\
\text { necesita ayuda para colocar enemas o supositorios. }\end{array}$ \\
\hline & 0 Incontinente. Más de un episodio semanal. \\
\hline Micción & \\
\hline & $\begin{array}{l}10 \text { Continente. No presenta episodios. Capaz de utilizar } \\
\text { cualquier dispositivo por sí solo (botella, sonda, orinal...). }\end{array}$ \\
\hline & $\begin{array}{l}5 \text { Accidente ocasional. Presenta un máximo de un episodio } \\
\text { en } 24 \text { horas o requiere ayuda para la manipulación de } \\
\text { sondas o de otros dispositivos. }\end{array}$ \\
\hline 0 & Incontinente. Más de un episodio en 24 horas. \\
\hline
\end{tabular}




\begin{tabular}{|c|c|c|c|c|}
\hline \multicolumn{5}{|l|}{ Ir al retrete } \\
\hline & 10 & \multicolumn{3}{|c|}{$\begin{array}{l}\text { Independiente. Entra y sale solo y no necesita ayuda } \\
\text { alguna por parte de otra persona. }\end{array}$} \\
\hline & 5 & \multicolumn{3}{|c|}{$\begin{array}{l}\text { Necesita ayuda. Capaz de manejarse con una pequeña } \\
\text { ayuda; es capaz de usar el cuarto de baño. Puede limpiarse. }\end{array}$} \\
\hline & 0 & \multicolumn{3}{|c|}{$\begin{array}{l}\text { Dependiente. Incapaz de acceder a él o de utilizarlo sin } \\
\text { ayuda mayor. }\end{array}$} \\
\hline \multicolumn{5}{|c|}{ Transferencia (traslado cama/sillón) } \\
\hline & 15 & \multicolumn{3}{|c|}{$\begin{array}{l}\text { Independiente. No requiere ayuda para sentarse o } \\
\text { levantarse de una silla, ni para entrar o salir de la cama. }\end{array}$} \\
\hline & & \multicolumn{3}{|c|}{$\begin{array}{l}\text { Mínima ayuda. Incluye una supervisión o una pequeña } \\
\text { ayuda física. }\end{array}$} \\
\hline & 5 & \multicolumn{3}{|c|}{$\begin{array}{l}\text { Gran ayuda. Precisa ayuda de una persona fuerte o } \\
\text { entrenada. }\end{array}$} \\
\hline & 0 & \multicolumn{3}{|c|}{$\begin{array}{l}\text { Dependiente. Necesita una grúa o el alzamiento de dos } \\
\text { personas. Es incapaz de permanecer sentado. }\end{array}$} \\
\hline \multicolumn{5}{|c|}{ Deambulación } \\
\hline & & \multicolumn{3}{|c|}{$\begin{array}{l}\text { Independiente. Puede andar } 50 \text { metros o su equivalente } \\
\text { en casa sin ayuda ni supervisión. Puede utilizar cualquier } \\
\text { ayuda mecánica excepto un andador. Si utiliza una } \\
\text { prótesis, puede ponérsela y quitársela solo. }\end{array}$} \\
\hline & 10 & \multicolumn{3}{|c|}{$\begin{array}{l}\text { Necesita ayuda. Necesita supervisión o una pequeña } \\
\text { ayuda física por parte de otra persona o utiliza andador. }\end{array}$} \\
\hline & 5 & \multicolumn{3}{|c|}{$\begin{array}{l}\text { Independiente en silla de ruedas. No requiere ayuda ni } \\
\text { supervisión. }\end{array}$} \\
\hline \multicolumn{5}{|c|}{ Subir y bajar escaleras } \\
\hline & 10 & \multicolumn{3}{|c|}{$\begin{array}{l}\text { Independiente. Capaz de subir y bajar un piso sin ayuda ni } \\
\text { supervisión de otra persona. }\end{array}$} \\
\hline & 5 & \multicolumn{3}{|c|}{ Necesita ayuda o supervisión. } \\
\hline & 0 & \multicolumn{3}{|c|}{ Dependiente. Es incapaz de salvar escalones. } \\
\hline $\begin{array}{l}\text { La } \\
\text { incapacidad } \\
\text { funcional se } \\
\text { valora como: }\end{array}$ & & $\begin{array}{l}\text { evera: }<45 \text { puntos. } \\
\text { rave: } 45-59 \text { puntos. }\end{array}$ & $\begin{array}{l}\text { * Moderada: } 60-80 \text { puntos. } \\
\text { * Ligera: } 80-100 \text { puntos. }\end{array}$ & $\begin{array}{l}\text { Puntuación } \\
\text { Total: }\end{array}$ \\
\hline
\end{tabular}

